

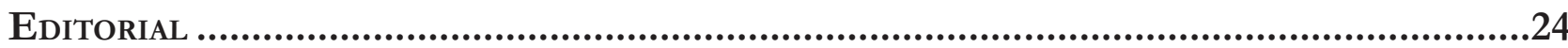

O Direito na fronteira da razão: Psicologia, neurociência e economia comportamental................... 24 Patrícia Perrone Campos Mello e Sergio Nojiri

I. NeURodireito: COGNIÇão, EMOÇÃo, JUÍZOS MORAIS E CIÊNCIA ..........................................26

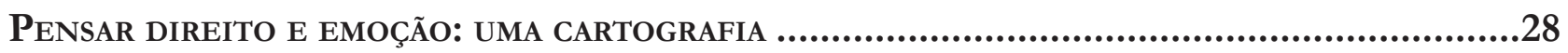

Nevita Maria Pessoa de Aquino Franca Luna

Neurodireito: o início, o fim E O MEIO

Carlos Marden e Leonardo Martins Wykrota

ENSAIO JURÍDICO SOBRE A RACIONALIDADE HUMANA: MAIORES, CAPAZES E IRRACIONAIS

André Perin Schmidt Neto e Eugênio Facchini Neto

DIVERGÊNCIAS DE PRINCÍPIO: ARGUMENTOS JURÍDICOS E MORAIS EM UM CENÁRIO DE DESACORDOS SOCIAIS

André Matos de Almeida Oliveira, Pâmela de Rezende Côrtes e Leonardo Martins Wykrota

CONSILIÊNCIA E A POSSIBILIDADE DO NEURODIREITO: DA DESCONFIANÇA À RECONCILIAÇÃO DISCIPLINAR.....

Thaís de Bessa Gontijo de Oliveira e Renato César Cardoso

MODELOS DE MORALIDADE

Molly J. Crockett

A INFELIZ BUSCA POR FELICIDADE No DiREITo

Úrsula Simões da Costa Cunha Vasconcellost, Noel Struchiner e Ivar Hannikainen

Além da liberdade: PersPeCtivas Em Nietzsche.

Lucas Costa de Oliveira

A mediaÇão de CONFlitos SOb a PERSPECTIVA do DESENVOLVIMENTO HUMANO: AS CONTRIBUIÇÕES DA PSICOLOGIA POSITIVA

Simone de Biazzi Ávila Batista da Silveira e Deise Brião Ferraz

Neuroimagiologia e aValiação de ResPonsabilidade

Nicole A. Vincent 
ANÁLISE CRÍTICA DA ORIENTAÇÃO DE CIDADÃOS COMO MÉTODO PARA OTIMIZAR DECISÕES PÚBLICAS POR MEIO DA TÉCNICA NUDGE.

Luciana Cristina Souza, Karen Tobias França Ramos e Sônia Carolina Romão Viana Perdigão

Políticas públicas e o deVer de monitoramento: “LEVANdo os Direitos A SÉrio". .252 Ana Paula de Barcellos

Nudges E POLÍticas PÚblicas: uM MECANISMO DE COMBATE AO TRABALHO EM CONDIÇÃo ANÁLOGA À DE ESCRAVO .267

Amanda Carolina Souza Silva, Débhora Renata Nunes Rodrigues e Saul Duarte Tibaldi

REDUZINDO A TRIBUTAÇÃO COGNITIVA: LIÇÕES COMPORTAMENTAIS PARA A DIMINUIÇÃO DOS EFEITOS PSICOLÓGICOS ADVERSOS DA POBREZA.............................................................288 Leandro Novais e Silva, Luiz Felipe Drummond Teixeira, Gabriel Salgueiro Soares e Otávio Augusto Andrade Santos

Políticas PÚBLICAS EM SUICÍDIO: DO PATERNALISMO CLÁSSICO AO PATERNALISMO LIBERTÁRIO E NUDGING

Davi de Paiva Costa Tangerino, Gabriel Cabral e Henrique Olive

Nudges COMO POLÍticA PÚbliCA PARA AUMENTAR O ESCASSO NÚMERO DE DOADORES DE ÓRGÃos PARA TRANSPLANTE

Roberta Marina Cioatto e Adriana de Alencar Gomes Pinheiro

Os PROGRAMAS DE INTEGRIDADE PARA CONTRATAÇÃO COM A ADMINISTRAÇÃO PÚBLICA ESTADUAL: NUDGE OU OBRIGAÇÃo LEGAL? UM OLHAR SOBRE AS DUAS PERSPECTIVAS .386

Cíntia Muniz Rebouças de Alencar Araripe e Raquel Cavalcanti Ramos Machado

Paternalismo libertário e Proteção JURídica do AMbiente: POR QUe PROTEger o AMBIENTE TAMBÉM DEVE SER PROTEGER AS LIBERDADES?

Mariana Carvalho Victor Coelho e Patryck de Araujo Ayala

Políticas PÚblicas baseadas EM EVIdÊNCIAS COMPORTAMENTAIS: REFLEXões A PARTIR do Projeto de Lei 488/2017 do Senado

Pâmela de Rezende Côrtes, André Matos de Almeida Oliveira e Fabiano Teodoro de Rezende Lara

III. ECONOMIA COMPORTAMENTAL: VIESES COGNITIVOS E POLÍTICAS PÚBLICAS .455

ECONOMIA COMPORTAMENTAL E DIREITO: A RACIONALIDADE EM MUDANÇA Marcia Carla Pereira Ribeiro e Victor Hugo Domingues

VIESES COGNITIVOS E DESENHO DE POLÍTICAS PÚBLICAS 
A neurociênCia da moralidade na tomada de DeCisões Jurídicas Complexas e No DESENHO DE POLÍTICAS PÚBLICAS

Erik Navarro Wolkart

Desvio de CARÁter ou SIMPLESMENTE HUMANO? ECONOMIA COMPORTAMENTAL APLICADA AO COMPORTAMENTO DESONESTO

Diana Orghian, Gabriel Cabral, André Pinto e Alessandra Fontana

Políticas Públicas e a ConcretizaÇão de direitos sociais: TOMAdA DE DECisão, ARQUITETURA DE ESCOLHAS E EFETIVIDADE

Ana Elizabeth Neirão Reymão e Ricardo dos Santos Caçapietra

BEHAVIORAL ECONOMICS E DIREITO DO CONSUMIDOR: NOVAS PERSPECTIVAS PARA O ENFRENTAMENTO DO SUPERENDIVIDAMENTO .568

Samir Alves Daura

A EDUCAÇÃo FORMAL PARA O CONSUMO É GARANTIA PARA UMA PRESENÇA REFLETIDA DO CONSUMIDOR NO MERCADO? UMA ANÁLISE COM BASE NA BEHAVIORAL LAW AND ECONOMICS (ECONOMIA COMPORTAMENTAL) 600

Marcia Carla Pereira Ribeiro e Edson Mitsuo Tiujo

LIBET, DETERMINISMO E CONSUMO: AS INFLUÊNCIAS DO MARKETING E A RELEVÂNCIA DA DELIBERAÇÃo CONSCIENTE NA SUPERAÇÃo CONDICIONAL DE HÁBITOS DE CONSUMO PERIGOSOS616 Émilien Vilas Boas Reis e Leonardo Cordeiro de Gusmão

CiÊNCIA DO DIREITO TRIBUTÁRIO, ECONOMIA COMPORTAMENTAL E EXTRAFISCALIDADE. .640 Hugo de Brito Machado Segundo

IV. CoMportamento JUdiCiAL: INFLUÊNCIA DE FATORES EXTRAJURÍDicos .660

FATORES METAPROCESSUAIS E SUAS INFLUÊNCIAS PARA A FORMAÇÃo DA DECISÃo JUDICIAL .662 Rogério Roberto Gonçalves de Abreu, Lúcio Grassi de Gouveia e Virgínia Colares

“A VIDA COMO ELA É": COMPORTAMENTO ESTRATÉGICO NAS CORTES Patrícia Perrone Campos Mello

A COMPOSIÇÃo do ÓRGão COLEGIAdo E SEUS EFEITOS NA TOMADA DE DECISÃo .720 André Garcia Leão Reis Valadares

Das 11 ilhas ao centro do arquipélago: os superpoderes do Presidente do STF DURANTE O RECESSO JUDICIAL E FÉRIAS .741 José Mário Wanderley Gomes Neto e Flávia Danielle Santiago Lima 
RAZÃo, EMOÇÃo E DELIBERAÇÃO: AS ADEQUAÇÕES REgIMENTAIS do SUPERIOR TribUNAL DE JUSTIÇA PARA A FORMAÇÃo DE PRECEDENTES EFICAZES

Peter Panutto e Lana Olivi Chaim

Heurística de ancoragem e fiXaÇÃo de danos morais em JUizados especiais Cíveis no Rio DE JANEIRO: UMA NOVA ANÁLISE 778

Fernando Leal e Leandro Molhano Ribeiro

LA PROTECCIÓN DE LOS DERECHOS POLÍTICOS FRENTE A LAS FUNCIONES DISCIPLINARIAS DE LAS AUTORIDADES ADMINISTRATIVAS: SUBSIDIARIEDAD Y DEFERENCIA EN EL SISTEMA INTERAMERICANO DE DERECHOS HUMANOS Jorge Ernesto Roa Roa

V. A influênCia do gÊNERo no PROCESSO DECisório JUdiCial

Como os Juízes decidem os Casos de estupro? ANALISANDo SENTENÇAS SOb A PERSPECTIVA DE VIESES E ESTEREÓTIPOS DE GÊNERO 826 Gabriela Perissinotto de Almeida e Sérgio Nojiri

GÊNERO E COMPORTAMENTO JUDICIAL NO SUPREMO TRIBUNAL FEDERAL: OS MINISTROS CONFIAM MENOS EM RELATORAS MULHERES?

Juliana Cesario Alvim Gomes, Rafaela Nogueira e Diego Werneck Arguelhes

Hércules, Hermes e a Pequena Sereia: uma reflexão sobre estereótipos de gênero, SUBPRESENTAÇÃo DAS MULHERES NOS TRIBUNAIS E (I)LEGITIMIDADE DEMOCRÁTICA DO PODER JUDICIÁRIO. .878 Jane Reis Gonçalves Pereira e Renan Medeiros de Oliveira

Prisão Cautelar de gestantes: análise do Fundamento filosófico da decisão do Habeas CoRpus N. 143.641 912

Artur César Souza e Giovania Tatibana de Souza

VI. Neurodireito APlicado ao direito E Ao Processo PENAL....................................926

CÉREbros QUe PUNEM: UMA REVISÃo CRÍTICA DA NEURoCIÊNCIA DA PUNIÇÃo .....................928 Ricardo de Lins e Horta

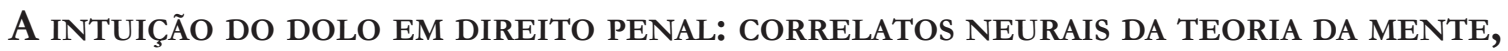
RACIOCÍNIO INDUTIVO E A GARANTIA DA CONVICÇÃO JUSTIFICADA. .946 Thiago Dias de Matos Diniz e Renato César Cardoso

As COMUNIDADES EPISTÊMICAS PENAIS E A PRODUÇÃo LEGISLATIVA EM MATÉRIA CRIMINAL..... 961 Stéphane Enguéléguélé 
DELINQUÊNCIA JUVENIL: RELAÇÕES ENTRE DESENVOLVIMENTO, FUNÇÕES EXECUTIVAS E COMPORTAMENTO SOCIAL NA ADOLESCÊNCIA .

André Vilela Komatsu, Rafaelle CS Costa e Marina Rezende Bazon

Límites TEMPORALES A LAS PENAS PRIVATIVAS DE LIBERTAD ATENDIENDO AL DESARROLLO PSICOSOCIAL.

Silvio Cuneo Nash

NEURolaw E AS PERSPECTIVAS PARA UMA ANÁLISE OBJETIVA DO COMPORTAMENTO SUGESTIONADO: REPERCUSSÃO DAS FALSAS MEMÓRIAS NA ESFERA PENAL

Mariana Dionísio de Andrade, Marina Andrade Cartaxo e Rafael Gonçalves Mota

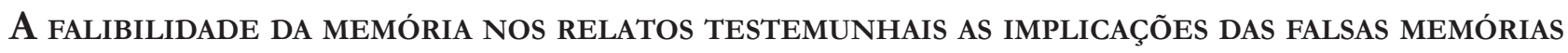
NO CONTEXTO DOS CRIMES CONTRA A DIGNIDADE SEXUAL

Caroline Navas Viana

A (IR)REPETIBILIDADE dA PROVA PENAL DEPENDENTE DA MEMÓRIA: UMA DisCUSSÃo COM BASE NA PSICOLOGIA DO TESTEMUNHO. 1058

William Weber Cecconello, Gustavo Noronha de Avila e Lilian Milnitsky Stein 


\title{
A neurociência da moralidade na tomada de decisões jurídicas complexas e no desenho de políticas públicas*
}

\author{
The neuroscience of morality, hard cases \\ decision-making process and the public \\ policies design
}

Erik Navarro Wolkart**

\section{Resumo}

O presente artigo aborda o problema da utilização de princípios gerais de justiça como premissa para a tomada de decisões jurídicas complexas e para o desenho de políticas públicas, o que, frequentemente, provoca resultados que diminuem o bem-estar social geral. Propõe-se adoção da neurociência da moralidade (e o pragmatismo profundo, daí decalcado) como guia filosófico para esse desenho, sempre focado nas consequências das políticas públicas para o bem-estar social. As matrizes teóricas aqui utilizadas são a economia do bem-estar, a análise econômica do e o utilitarismo. A metodologia é a revisão de literatura a respeito do tema. Relatando diversos experimentos neurocientíficos, demonstraremos como nosso cérebro incide, sistematicamente, em erros de julgamento que fazem crer na utilização preponderante de princípios de justiça no desenho de políticas públicas, em detrimento do aumento do bem-estar social. Inicialmente, apresentaremos o novo campo filosófico conhecido como neurociência da moralidade. Posteriormente, descreveremos a forma dual de funcionamento do cérebro, demonstrando a origem de nossos instintos e sentimentos de justiça. Finalmente, revelaremos como o pragmatismo pode auxiliar o debate de questões difíceis para o desenho correto de políticas públicas, considerando a forma dual de funcionamento da mente, bem como os erros cognitivos a que estamos sujeitos, o que é inédito no direito brasileiro. Concluiremos que teorias que conferem caráter preponderante a princípios de justiça nada mais são do que racionalizações de julgamentos intuitivos e imprecisos de nosso cérebro, de modo que devem ceder espaço para premissas utilitaristas na tomada de decisões jurídicas complexas e no desenho de políticas públicas, essas sim, capazes de elevar o nível de bem-estar social.

Palavras-chave: Direito. Neurociência. Economia. Bem-estar Social.

* Recebido em 11/06/2018 Aprovado em 16/07/2018

** Juiz Federal, Doutor em Direito pela UERJ em colaboração com a Harvard Law School. Email: eriknavarrowolkart@gmail.com

\section{Abstract}

This paper deals with the use of the neuroscience of morality (and deep pragmatism, derived from it) as a philosophical guide for hard cases decision-making process and the public policies design. The theoretical matri- 
ces which will be used are the welfare economics, the economic analysis of law and the utilitarianism. By reporting on various neuroscientific experiments, we will demonstrate how our brain systematically makes mistakes that lead us to believe that the design of public policies needs to be based on principles of justice to the detriment of increasing social welfare. Initially, we will present the new philosophical field known as neuroscience of morality. Afterwards, we will describe the dual-process brain, demonstrating the origin of our instincts and feelings of justice. Finally, we will demonstrate how pragmatism can help to debate hard questions for the correctness of public policies designing, considering the dual process brain, and the bounded rationality. This framework is unprecedented in the Brazilian law. We conclude that theories based mainly on principles of justice derive from rationalizations of our intuitions and our cognitive biases so that they must give room to utilitarian premises in the design of public policies, which in turn must be focused exclusively in increasing social welfare.

Keywords: Law. Neuroscience. Economics. Social Welfare

\section{INTRODUÇÃo}

O presente artigo trata da utilização da neurociência da moralidade (e do pragmatismo profundo, daí decalcado) como guia filosófico na tomada de decisões jurídicas complexas e no desenho de políticas públicas que delas decorram. Acreditamos que, no Brasil, a confecção de políticas públicas, aí incluídas a elaboração e a interpretação da lei, baseia-se precipuamente em princípios absolutos de justiça, normalmente de matriz kantiana, conferindo-se pouca atenção para seu impacto no aumento do bem-estar social, o que é problemático.

A utilização da neurociência da moralidade como guia é uma tentativa de conferir maior cientificidade a essa atividade. É, ainda, uma busca pelo fortalecimento da matriz utilitarista na condução da coisa pública, na medida em que a neurociência revela as fraquezas do kantianismo enquanto fruto de nossas próprias limitações cognitivas.

Apresentaremos a Neurociência da Moralidade como campo científico e filosófico, focando principalmente na forma dual de funcionamento do cérebro. Posteriormente, utilizando diversos experimentos derivados do Dilema do bonde desgovernado, demonstraremos como nosso julgamento intuitivo é, às vezes, inconsistente e como ele se relaciona com nossos sentimentos de justiça. $\mathrm{Na}$ sequência, veremos que os imperativos categóricos kantianos são racionalizações de nossos instintos, que funcionam bem na maioria das vezes, mas que, em alguns casos, podem levar a julgamentos inconsistentes e dissociados da realidade. Por fim, com base no conhecimento das estruturas envolvidas nos dois modos de pensar do cérebro, estudaremos como é possível afastar os erros de julgamento na tomada de decisões importantes sobre questões difíceis. Concluiremos que, na tomada de decisões jurídicas complexas e no desenho de políticas públicas, a rapidez imprecisa do modo instintivo de pensar deve ceder a ponderações racionais de base científica, sempre calcadas no aumento do bem-estar social.

No nosso estudo, utilizamos, preponderantemente, as pesquisas de Joshua Greene. Greene é neurocientista e fundador do pragmatismo profundo, também conhecido como neurociência da moralidade. Sua obra é bastante técnica, mas de fácil compreensão. Suas pesquisas, todas muito recentes, mas bem-estabelecidas e utilizadas por um sem-número de cientistas, modernizaram o utilitarismo, atualizando-o e justificando-o pelas descobertas da neurociência. A vantagem da utilização desse tipo de pragmatismo é a sua capacidade de indicar caminhos para discussões de temas difíceis e polêmicos, como sói acontecer no desenho de políticas públicas. Essa abordagem, todavia, não traz formulas definitivas, mas tem a grande vantagem de evitar equívocos básicos do administrador e do jurista que, no afã de racionalizar seus instintos de justiça, acabam descuidando do verdadeiro objetivo do Estado Democrático de Direito, que é a promoção do bem-comum. 


\section{A Neurociência da Moralidade}

A neurociência da moralidade (ou pragmatismo profundo) pode ser considerada como uma atualização da filosofia utilitarista ${ }^{1}$, renovada e fortificada pelos fantásticos avanços científicos da neurociência e da psicologia. Trata-se da revisão de paradigmas filosóficos das teorias morais com base em insights neurocientíficos. Fundada por vários pesquisadores, ${ }^{2}$ essa nova fronteira tem por pressuposto uma das mais importantes descobertas da psicologia moderna, a Teoria do Sistema Dual de Pensamento (dualprocess brain) fundada por Seymor Epstein, Johnathan Evans ${ }^{3}$, Steven Sloman, Keith Stanovich e Richard West ${ }^{4}$, mas popularizada no best-seller de Daniel Kahneman "Thinking, fast and slow"

A hoje bem estabelecida Teoria das Duas Formas de Pensar (Dual Process Brain) pode ser assim resumida: por razões evolutivas, nosso cérebro desenvolveu-se com dois sistemas de funcionamento do pensamento que atuam de forma paralela e complementar: o sistema intuitivo, chamado de sistema 1, e o sistema reflexivo, denominado sistema 2. O sistema 1 é rápido, eficiente, automático, inconsciente e pouco preciso. Foi moldado para oferecer uma avaliação contínua dos problemas que um organismo deve resolver para sobreviver. Já o sistema 2 é reflexivo, meticuloso, detalhista e lento. Ele procura sempre a precisão, buscando o maior número de dados para fazer uma pergunta ou dar uma resposta. ${ }^{6}$ Cada um desses sistemas funciona com base em específicas estruturas cerebrais ${ }^{7}$, mas eles atuam de modo conjugado, de forma que mesmo o sistema reflexivo funciona influenciado por informações rapidamente oferecidas pelo sistema intuitivo.

Exemplos ajudam a demonstrar como esses sistemas funcionam. Todorov e colaboradores demonstraram como o sistema 1 avalia, rapidamente, a segurança da nossa interação com estranhos (por exemplo, alguém de uma tribo diferente da nossa) por meio dos olhos e da expressão facial ${ }^{8}$. De acordo com a pesquisa, ao divisarmos o rosto de alguém, nosso cérebro julga até que ponto aquela pessoa é ameaçadora (ou seja, dominante, o que se dá pelo formato quadrado do rosto) e confíavel (pelas expressões faciais, principalmente o sorriso $)^{9}$.

Todorov demonstra por ultrassonografia que esse tipo de julgamento intuitivo envolve a participação de regiões cerebrais específicas, o que sugere sua importância na nossa história evolutiva ${ }^{10}$. Todavia, como esses julgamentos são, algumas vezes, dissociados da realidade, acabam causando influências perniciosas eventuais

1 Que, aliás, está sempre em evolução. CALABRESI, Guido. The Future of Law and Economics. New Haven, CT: Yale University, 2016. p. 6

2 Como Joshua Greene, Jonathan Cohen, R. Brian Sommerville, John Darley e outros. (GREENE, Joshua D. et al. An fMRI Investigation of Emotional Engagement in Moral Judgment. Science, v. 293, n. 5.537, p. 2.105-2.108, set. 2001; NEERGAARD, L. Brain Scan Shows Emotion in Decisions. Washington Post, set. 2001; NEARY, Walter. Personal Decisions Exercise the Emotional Part of the Brain, 2001. Disponível em: <http://www.washington.edu/news/2001/11/26/personal-decisions-exercise-the-emotional-partof-the-brain>. Acesso em: 16 fev. 2018).

3 Apesar de Locke, Descartes, Freud e outros intuírem e até mesmo trabalharem com a contraposição raz̧ão e intuição, a primeira Teoria do Dual Process tem por figura central Johnatan Evans e seus trabalhos nas décadas de 1970 e 1980. Kahneman e Tversky aportaram importantes contribuições à forma intuitiva de pensar com seus estudos sobre heurísticas e vieses. Já as teorias mais influentes do sistema dual (que define que as duas formas de pensar são devidas a dois sistemas diferentes) são devidas a Sloman, Evans e Over, Stanovich, e Epstein nos anos 1990. Para um histórico completo do desenvolvimento do tema, ver: FRANKISH, Keith. Dual-Process and Dual-System Theories of Reasoning. Philosophy Compass, v. 5, n. 10, p. 914-926, 2010.

4 STANOVICH, Keith E.; WEST, Richard F. Individual Differences in Reasoning: Implications for the Rationality Debate? Behavioral and Brain Sciences, v. 23, n. 5, p. 645-726, out. 2000.

5 KAHNEMAN, Daniel. Thinking: fast and slow. New York: Farrar, Straus and Giroux, 2011. [Kindle]. location 249.

6 KAHNEMAN, Daniel. Thinking: fast and slow. New York: Farrar, Straus and Giroux, 2011. [Kindle], location 266.

7 FRANKISH, Keith. Dual-Process and Dual-System Theories of Reasoning. Philosophy Compass, v. 5, n. 10, p. 914-926, 2010.

8 TODOROV, Alexander; BARON, Sean G.; OOSTERHOF Nikolaas N. Evaluating Face Trustworthiness: A Model Based Approach. Social Cognitive and Affective Neuroscience, v. 3, n. 2, p. 119-127, jun. 2008.

9 Veja-se que esse é um julgamento extremamente impreciso. Quantas pessoas pouco confiáveis têm um sorriso estampado no rosto?

10 TODOROV, Alexander; PAKRASHI, Manish; OOSTERHOF Nikolaas N. Evaluating Faces on Trustworthiness after Minimal Time Exposure. Social Cognition, v. 27, n. 6, p. 813-833, 2009. 
em processos sociais importantes como nas eleições democráticas ${ }^{11}$.

Essa pesquisa aponta, ainda, para uma ancoragem entre o raciocínio reflexivo e o raciocinio intuitivo. $\mathrm{O}$ sistema reflexivo, quanto menos informado, mais ancora suas reflexões e deliberações no sistema intuitivo. Demonstrou-se, por exemplo, que, quanto menos educado e informado o eleitorado, maior a importância do sistema 1 no processo. Pesquisas posteriores apontaram que a influência da chamada competência facial do candidato — uma combinação entre as características faciais de dominância (por exemplo: queixo quadrado) e de confiança (por exemplo: sorriso) — é três vezes maior entre o eleitorado pobre que assiste televisão por muitas horas, quando comparada com a influência no eleitorado mais bem informado e abastado ${ }^{12}$.

Por ser veloz, o sistema 1 trabalha com preconcepções e memórias armazenadas por nossa história evolutiva, além de recordações de experiências da vida. Diante da necessidade de prover respostas, esse sistema apresenta respostas simples (heurísticas) e pré-concebidas (vieses), que podem ou não corresponder à realidade.

Já o sistema 2 trabalha sempre buscando dados e racionalizando. O problema é que, como vimos nas pesquisas de Todorov, o sistema 2 acaba racionalizando sobre os dados ofertados pelo sistema 1 (ancoragem). Ele supervisiona essas respostas prontas que o sistema 1 traz automaticamente (respostas default), ora endossando-as, ora alterando-as ou mesmo substituindo-as por outras mais rentes aos dados reais ${ }^{13}$. Isso pode ser extremamente eficiente em alguns casos, mas pode causar erros grotescos de avaliação em outros ${ }^{14}$.

Por exemplo, em uma pesquisa ${ }^{15}$ que se seguiu a um acidental derramamento de óleo com impactos em

11 TODOROV, Alexander et al. Inferences of Competence from Faces Predict Election Outcomes. Science, v. 308 , n. 5.728 , p. 1.623-1.626, 10 jun. 2005.

12 LENZ, Gabriel S.; LAWSON, Chappell. Looking the Part: Television Leads Less Informed Citizens to Vote Based on Candidates' Appearance. American Journal of Political Science, v. 55, n. 3, p. 574-589, jul. 2011. Os autores assim resumem sua descoberta: "Specifically, we test whether the effect of appearance is more pronounced among those who know little about politics but are exposed to visual images of candidates. To do so, we combine appearance-based assessments of U.S. Senate and gubernatorial candidates with individual-level survey data measuring vote intent, political knowledge, and television exposure. Confirming long-standing concerns about image and television, we find that appealing-looking politicians benefit disproportionately from television exposure, primarily among less knowledgeable individuals."

13 KAHNEMAN, Daniel; SHANE Frederick. Representativeness Revisited: Attribute Substitution in Intuitive Judgment. In: GILOVICH, Thomas; GRIFFIN, Dale; KAHNEMAN, Daniel (Eds.). Heuristics and Biases: The Psychology of Intuitive Judgment. Cambridge: Cambridge University, 2002. p. 49-81.

14 Frankish apresenta uma tabela bastante atual das diferenças entre a forma de pensar intuitiva (protagonizada pelo sistema 1) e a forma de pensar reflexiva (devida ao sistema 2). (FRANKISH, Keith. Dual-Process and Dual-System Theories of Reasoning. Philosophy Compass, v. 5, n. 10, p. 914-926, 2010. p. 924).

\begin{tabular}{lll}
\hline & System 1 & System 2 \\
\hline Processes & Fast & Slow \\
& Automatic & Controlled \\
& Nonconscious or preconscious & Conscious \\
& Low effort, high capacity & High effort, low capacity \\
& Heuristic & Analytic \\
& Associative & Rule-based \\
Attitudes & Implicit & Explicit \\
& Cultural stereotypes & Personal beliefs \\
& Slow acquisition and change & Fast acquisition and change \\
& Fast access & Slow access \\
Content & Actual & Hypothetical \\
& Concrete & Abstract \\
& Contextualised & Decontextualised \\
& Domain-specific & Domain-general \\
Architecture & A set of systems, modular & A single system \\
& Parallel & Serial \\
& Does not use working memory & Uses working memory \\
Evolution & Evolutionarily old & Evolutionarily recent \\
& Shared with animals & Unique to humans \\
& Nonverbal & Language involving \\
& Serves genetic goals ('short leash' control) & Serves individual goals ('long-leash' control) \\
Variation & Independent of general intelligence & Linked to general intelligence \\
& Little variation across cultures and individuals & Variable across cultures and individuals \\
& Relatively unresponsive to verbal instruction & Responsive to verbal instruction \\
\hline
\end{tabular}


aves nativas, perguntou-se quanto as pessoas estariam dispostas a doar para salvar, respectivamente, 2 mil, 20 mil, ou 200 mil pássaros. Os valores ficaram em 80, 78 e 88 dólares, respectivamente, e nem de longe correspondem ao número de pássaros a serem salvos. Verificou-se que o que realmente compeliu as pessoas a doarem valores maiores não foram os números (dados que seriam os mais relevantes para a definição do montante), mas a apresentação da imagem de uma ave desamparada, afogando-se com as penas encharcadas de óleo. Isso ocorre porque as memórias evolutivas impregnadas no sistema 1 ancoram e enviesam os julgamentos do sistema $2^{16}$. Mais à frente, ao estudarmos as possibilidades cooperativas na fase cognitiva do processo, abordaremos técnicas de ancoragem como o priming, capazes de elevar o comportamento cooperativo, evitando, por exemplo, a litigância de má-fé.

Joshua Greene é autor de uma analogia para explicar o sistema dual de pensamento. Ele utiliza a imagem de uma câmera fotográfica, que pode operar de modo manual ou automático. A forma automática é rápida e tira boas fotos na maior parte das vezes, mas é pouco flexível a variações de luz e profundidade, por exemplo. Nessas circunstâncias, ela pode falhar. Já o modo manual é lento, exige conhecimento e esforço na operação. Todavia, quando utilizado, produz fotografias incríveis, mesmo em condições adversas ${ }^{17}$. $\mathrm{O}$ grande segredo de um bom fotógrafo é saber escolher o modo de operação correto para cada situação.

Morfologicamente, sabe-se que o sistema 1 funciona, preponderantemente, na região do córtex pré-frontal ventromedial (VMPFC), enquanto o sistema 2 é orquestrado pelo córtex pré-frontal dorso lateral (DLPFC). Como explica Greene, o córtex pré-frontal dorso lateral não é o responsável solitário pelo raciocínio reflexivo. Em verdade ele opera como um maestro, recebendo imputs de diversas regiões do cérebro, inclusive do córtex pré-frontal ventromedial ${ }^{18}$.

Pacientes com lesões no VMPFC apresentam problemas importantes para o processo tomada de decisão. Sobre o tema, são famosos os experimentos de Antônio Damasio, elaborados com base no trágico caso de seu paciente Phineas Gage. Recuperadas suas habilidades cognitivas após uma explosão que destruiu a região acima do nariz (atacando o VMPFC, mas preservando o sistema 2, o DLPFC), Gage tornou-se um péssimo tomador de decisões, em razão de déficit emocional, ainda que fosse capaz de realizar operações matemáticas. Diversos experimentos apontam que a preservação de habilidades cognitivas com déficit emocional (to know but not to feel) ${ }^{19}$ implica, por exemplo, que apenas os efeitos imediatos das decisões passem a ser considerados ${ }^{20}$ pelo indivíduo, advindo daí trágicas consequências ${ }^{21}$, inclusive para possibilidades cooperativas estáveis ${ }^{22}$. Essa dependência do sistema 2 ao sistema 1 relembra o adágio de David Hume, que afirmava

DESVOUSGES, William H. et al. Measuring Nonuse Damages Using Contingent Valuation: An Experimental Evaluation of Accuracy. 2. ed. Research Triangle Park, NC: RTI, 2010. Disponível em: < https://www.rti.org/sites/default/files/resources/bk-0001-1009_ web.pdf>. Acesso em: 16 fev. 2018.

16 KAHNEMAN, Daniel. Thinking: fast and slow. New York: Farrar, Straus and Giroux, 2011. [Kindle], location 2.080.

17 GREENE, Joshua D. Moral Tribes: Emotion, Reason and the Gap Between Us and Them. New York: Penguin Books, 2013. p. 137.

18 GREENE, Joshua D. Moral Tribes: Emotion, Reason and the Gap Between Us and Them. New York: Penguin Books, 2013. p. 122-123.

19 DAMASIO, Antônio. Descartes' Error: Emotion, Rationality and the Human Brain. New York: Penguim; Grosset, 1994. [Kindle]. p. 45.

20 BECHARA, Antonie et al. Insensitivity to Future Consequences Following Damage to Human Prefrontal Cortex. Cognition, v. 50 , p. $7-15,1994$.

21 Por exemplo, impossibilidade de manter um emprego, ou uma família. Há, em verdade, completa perda do senso de responsabilidade, e uma quase total impossibilidade de fazer escolhas óbvias na vida real, ainda que, em teoria, o paciente compreenda tudo e faça escolhas corretas. O que se dá é uma incapacidade de aprender com os erros. O VMPFC retém experiências ruins em forma de emoções e transfere essa informação ao DLPFC, que aprende e corrige a postura. (DAMASIO, Antônio. Descartes' Error: Emotion, Rationality and the Human Brain. New York: Penguim; Grosset, 1994. [Kindle]. p. 34-35 e 49; GREENE, Joshua D. Moral Tribes: Emotion, Reason and the Gap Between Us and Them. New York: Penguin Books, 2013. p. 142).

22 Há evidências de um egoísmo exacerbado, que não leva em conta possibilidades cooperativas futuras. (THOMAS, Bradley C. et al. Arrested Development: Early Prefrontal Lesions Impair the Maturation of Moral Judgement. Brain: A Journal of Neurology, v. 137 , n. 4, p. 1.254-1.261, abr. 2014). 
que a razão é a escrava das paixões ${ }^{23}$.

Por outro lado, pacientes com lesões severas no DLPFC (o oposto do ocorrido com Gage) perdem, completamente, a capacidade cognitiva, o grande diferencial humano ${ }^{24}$.

O que o funcionamento do cérebro de duas formas diferentes tem a ver com a filosofia da moralidade? Segundo Greene e colegas, tudo ${ }^{25}$. Se a engrenagem mental formada por dois sistemas foi a forma escolhida pela natureza para nos tornar a espécie dominante do planeta, cabe-nos utilizá-la da melhor forma, desenvolvendo uma espécie de habilidade capaz de dizer qual o melhor sistema a preponderar para cada tipo de situação ${ }^{26}$.

Nossa preocupação não são os casos em que decisões muito rápidas ou ligadas à sobrevivência são tomadas, mas sim aqueles que envolvem temas complexos da modernidade, aí incluída a escolla de politicas públicas. É principalmente nesses casos que escolhas feitas com base preponderante nos instintos podem ser extremamente traiçoeiras.

\section{Explicando as traições do sistema 1: a troleologia de Joshua Greene}

Ao longo dos últimos vinte anos, Joshua Greene e outros cientistas ${ }^{27}$ vêm utilizando variações do famoso dilema do bonde desgovernado (trolley problem) para, com o auxílio da ressonância magnética e de outras tecnologias, demonstrar as falhas de julgamento do sistema 1, colocando em xeque determinados princípios absolutos de justiça, e abrindo espaço para o avanço de parâmetros utilitaristas na confecção de políticas públicas ${ }^{28}$.

Tal como o dilema do prisioneiro, o problema do bonde tem sido usado por décadas para discutir importantíssimas questões éticas envolvendo o comportamento humano ${ }^{29}$.

Em uma das versões concebidas por Thompson, o dilema propõe o seguinte:

Um bonde desgovernado está prestes a atropelar e matar cinco pessoas (digamos, operários que trabalham nos seus trilhos ${ }^{30}$ ).

23 HUME, David. A Treatise of Human Nature. Oxford: Clarendon, 1896. [Kindle]. p. 274: "Reason is, outht only to be the slave of the passions, and can never pretend to any other office than to serve and obey them." A relação entre Hume e o dual process mode é de Greene (GREENE, Joshua D. Moral Tribes: Emotion, Reason and the Gap Between Us and Them. New York: Penguin Books, 2013. p. 122).

24 O sistema 2 só existe em serem humanos. (FRANKISH, Keith. Dual-Process and Dual-System Theories of Reasoning. Philosophy Compass, v. 5, n. 10, p. 914-926, 2010. p. 922).

25 GREENE, Joshua D. Moral Tribes: Emotion, Reason and the Gap Between Us and Them. New York: Penguin Books, 2013. p. $141-143$.

26 Para ser um bom motorista, por exemplo, primeiro é preciso apreender a dirigir, usando preponderantemente o sistema 2. Após, boa parte das tarefas da direção torna-se automática, operando-se a partir do sistema 1 (não todas, até porque decisões complexas são tomadas a todo instante quando dirigimos. Muitas delas, todavia, podem ser tomadas com rapidez, porque estão ancoradas em experiências já vividas e armazenadas no sistema 1. (GREENE, Joshua D. Moral Tribes: Emotion, Reason and the Gap Between Us and Them. New York: Penguin Books, 2013. p. 143).

27 BARON, J.; GREENE, J. D. Determinants of Insensitivity to Quantity in Valuation of Public Goods: Contribution, Warm Glow, Budget Constraints, Availability, and Prominence. Journal of Experimental Psychology, v. 2, n. 2, p. 107-125, 1996; GREENE, Joshua D. et al. An fMRI Investigation of Emotional Engagement in Moral Judgment. Science, v. 293, n. 5.537, p. 2.105-2.108, set. 2001.

28 Trata-se, no nosso entender, de uma revisitação do embate farness versus welfare, muito bem desenvolvido por Shavell e Kaplow, em KAPLOW, Louis; SHAVELL, Steven. Fairness Versus Welfare. Harvard Law Review, v. 114, n. 4, p. 961-1.390, fev. 2001.

29 O responsável pela montagem do modelo original foi Philippa Foot, em 1967 (FOOT, Philippa. The Problem of Abortion and the Doctrine of the Double Effect. Oxford Review, n. 5, p. 5-15, 1967). Nove anos depois, Thompson rediscutiu as ideias de Foot e criou importantes variações para o modelo. Recentemente, o tema foi revisitado por SANDEL, Michael. Justice: What's the Right Thing to Do? New York: Farrar, Straus and Giroux, 2008, p. 18. O tema atualmente vem ganhando enorme importância, principalmente em razão dos chamados "carros autônomos", cuja programação certamente enfrentará dilemas parecidos com o do bonde desgovernado. Nesse sentido: HUANG, Bert I. Book Review: Law and Moral Dilemmas. Harvard Law Review, v. 130, p. 659-699, dez. 2016, p. 661.

30 Comentário nosso 
Um homem muito gordo (suponhamos, um funcionário da ferrovia ${ }^{31}$ ) está em pé, sobre uma ponte, entre o bonde e os operários. Uma outra pessoa na mesma ponte percebe que, se empurrar o homem gordo, seu volume será capaz, de parar o bonde, matando-o, mas salvando as cinco pessoas. O dilema consiste em empurrar ou não o funcionário ${ }^{32}$.

Figura $1 \square$ Versão de Thompson do dilema do bonde desgovernado (footbridge case) ) $^{33}$

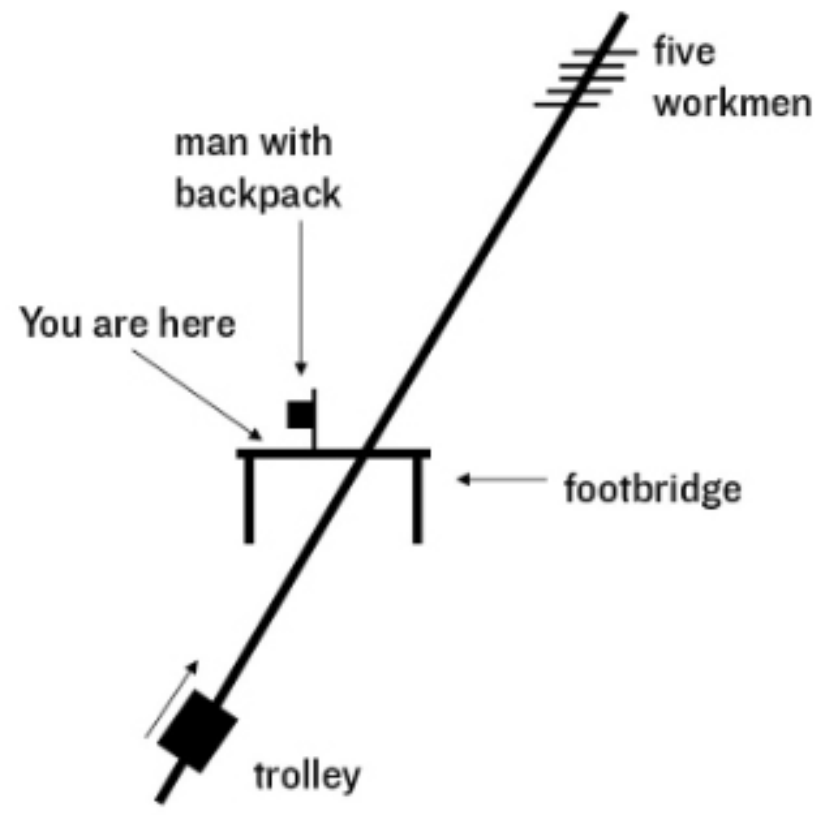

O dilema do bonde é, em verdade, um modelo simples, ${ }^{34}$ que contrapõe a busca de um bem maior com os direitos individuais fundamentais de alguém. Trata-se de uma espécie de contraposição artificial entre Kant e Mill ${ }^{35}$.

Grande parte dos textos que abordam o dilema concluem, kantianamente, que empurrar o funcionário da companhia seria errado ${ }^{36}$. Independentemente das consequências, empurrar o funcionário seria fundamentalmente errado, pois violaria o princípio categórico kantiano segundo o qual o ser humano jamais pode ser tratado como um meio, devendo, sempre, ser considerado como o fim de todas as coisas ${ }^{37}$.

31 Comentário nosso.

32 Adaptação do original: "George is on a footbridge over the trolley tracks. He knows trolleys, and can see that the one approaching the bridge is out of control. On the track back of the bridge there are five people; the banks are so steep that they will not be able to get off the track, in time. George knows that the only way to stop an out-of-control trolley is to drop a very heavy weight into its path. But the only available, sufficiently beavy weight, is a fat man, also watching the trolley from the footbridge. George can shove the fat man onto the track in the path of the trolley, killing the fat man; or he can refrain from doing this, letting the five die." (THOMSON, Judith. Killing, Letting Die, and the Trolley Problem. Monist: Journal of General Philosophical Inquiry, v. 59, n. 2, p. 204-217, 1976).

33 GREENE, Joshua D. Moral Tribes: Emotion, Reason and the Gap Between Us and Them. New York: Penguin Books, 2013. p. 114.

34 A utilidade de modelos desse tipo está não em propor qual escolha deveria ser feita na vida real — onde certamente as incertezas e as variáveis dariam pesos muito diferentes para as possibilidades em jogo - , mas sim em isolar os problemas morais envolvidos e permitir um estudo mais preciso a respeito. (SANDEL, Michael. Justice: What's the Right Thing to Do? New York: Farrar, Straus and Giroux, 2008. p. 22).

35 GREENE, Joshua D. Moral Tribes: Emotion, Reason and the Gap Between Us and Them. New York: Penguin Books, 2013, p. 116.

36 No dilema original de Foot, discutia-se, apenas, se o motorista do bonde deveria mudá-lo de direção, para matar uma pessoa ao invés de cinco. A autora conclui que não. Já Thompson, ao rever o dilema e propor suas variantes, traz resposta positiva para a questão (no dilema original), trazendo em seguida a complexidade do footbridge case. Curiosamente, em participação na obra recentíssima de F. M. Kamm, Judith Thomsom traz novos comentários sobre o tema, revendo sua posição e aderindo à posição inicial de Foot. Assim, para ela, hoje, não haveria dilema algum, e tanto a mudança de rota do bonde quanto o empurrão do funcionário da ponte seriam sempre errados. (THOMSON, Judith. Kamm on the Trolley Problems. In: KAMM, F. M. The Trolley Problem Mysteries. Oxford: Oxford University, 2016, p. 113-133. [Kindle]. p. 113).

37 GREENE, Joshua D. Moral Tribes: Emotion, Reason and the Gap Between Us and Them. New York: Penguin Books, 2013. p. 115; KANT, Immanuel. Fundamental Principles of the Metaphysics of Morals. Tradução Thomas Kingsmill Abbott. [Kindle: The ultimate 
Grande parte das críticas ao utilitarismo funda-se na suposta desvalorização dos direitos fundamentais, ao permitir sua violação eventual com fundamento nas consequências finais do ato. O que Greene e outros procuram provar é, de um lado, a inconsistência da máxima kantiana quando aplicada a variações do mesmo dilema e, a partir daí, que o utilitarismo não merece a crítica kantiana ${ }^{38}$.

Uma das primeiras variações do dilema (chamada de switch dilema), utilizada por Thomson ${ }^{39}$ e outros, é a seguinte:

Um bonde desgovernado está prestes a atropelar e matar cinco operários que trabalham nos seus trilhos. Uma pessoa encontra-se em pé, ao lado do trilho. Ao alcance de suas mãos está uma alavanca capaz. de mudar a direção do bonde para um outro trilho onde trabalha apenas um funcionário da companbia. Deve a pessoa acionar a alavanca para mudar a direção do bonde, evitando a morte dos cinco trabalhadores e permitindo a morte do funcionário?

$\mathrm{Na}$ figura 6, temos a representação gráfica dessa versão.

Figura 2 - Switch dilemma ${ }^{40}$

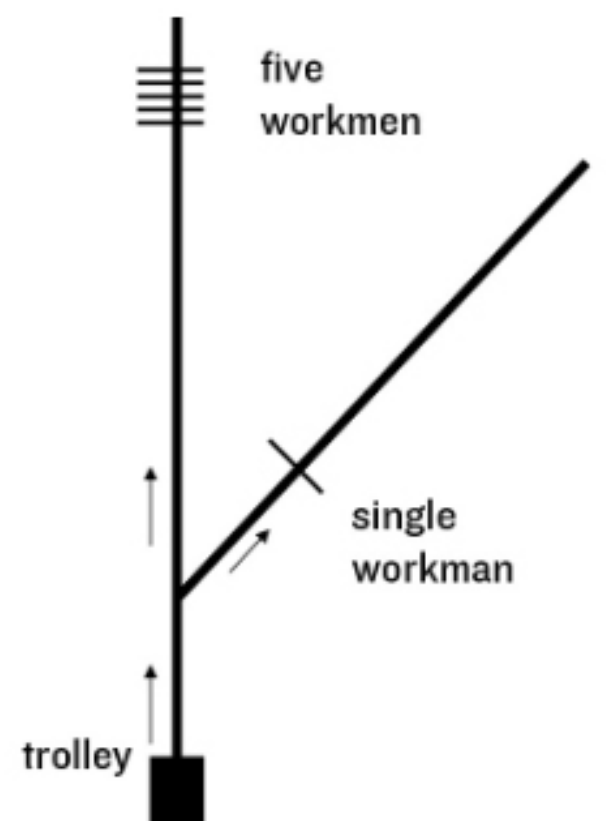

Nessa segunda versão, seria moralmente aceitável que se acionasse a alavanca? Thomson, que originalmente criou esse novo enredo, respondia afirmativamente ${ }^{41}$, bem como a maioria das pessoas, como veremos.

collected works of 14 books]. location 12.728 .

38 É interessante referir recentíssima pesquisa a respeito das questões morais envolvendo o dilema em países orientais. É surpreendente que, quando aplicado a budistas no Tibete (cidade de Lhasa), a aprovação moral do footbridge case chega a impressionantes 83\%, contra apenas 19\% em Guangzhou, na China. (XIANG, Xin. Would the Buddha Push the Man Off the Footbridge? Systematic Variations in the Moral Judgment and Punishment Tendencies of Han Chinese, Tibetans and Americans. 2014. Monografia (Trabalho de Conclusão de Curso). Harvard University, Cambridge, MA, 201 XIANG, Xin. Would the Buddha Push the Man Off the Footbridge?: Systematic Variations in the Moral Judgment and Punishment Tendencies of Han Chinese, Tibetans and Americans. 2014. f. Monografia--(Trabalho de Conclusão de Curso). Harvard University, Cambridge, MA, 2014).

39 Adaptação do original: "Frank is a passenger on a trolley whose driver has just shouted that the trolley's brakes have failed, and who then died from the shock. On the track abead are five people; the banks are so steep that they will not be able to get off the track in time. The track has a spur leading off to the right, and Frank can turn the train onto it. Unfortunately there is one person on the right-hand track. Frank can turn the train, killing the one; or he can refrain from turning the train, letting the five die." (THOMSON, Judith. Killing, Letting Die, and the Trolley Problem. Monist. Journal of General Philosophical Inquiry, v. 59, n. 2, p. 204-217, 1976, p. 207).

40 GREENE, Joshua D. Moral Tribes: Emotion, Reason and the Gap Between Us and Them. New York: Penguin Books, 2013. p. 115.

41 Como dissemos acima, em obra recentíssima, Thomson mudou de ideia. (THOMSON, Judith. Kamm on the Trolley Problems. In: KAMM, F. M. The Trolley Problem Mysteries. Oxford: Oxford University, 2016, p. 113-133. [Kindle]. p. 113). 
O que se pode ver, claramente, a partir dessas duas versões, quando nós mesmos respondemos à questão, é o fato de que nosso cérebro gera intuições diferentes para casos similares. A ação na versão original parece claramente errada, o que não acontece no segundo caso ${ }^{42}$.

A resposta a esse aparente conflito intuitivo sobre o que venha a ser moralmente correto pode ser extraída do acima referido dual-process system, aliado ao que Cohen denominou controle cognitivo, que é a babilidade de coordenar pensamento e ação de acordo com nossos objetivos ${ }^{43}$.

Um experimento clássico exemplifica bem as dificuldades do controle cognitivo: a tarefa de identificar a cor com que uma determinada palavra aparece projetada em uma tela (color-naming Stroop task). Indivíduos não têm qualquer dificuldade de acertar a tonalidade, salvo quando a palavra projetada refere o nome de outra cor. Por exemplo: se projetarmos a palavra vermelho em vermelho, pessoas sem limitações visuais cumprirão com facilidade a tarefa. Todavia, quando projetamos a palavra vermelho escrita em verde, boa parte das pessoas pronuncia vermelho, quando o correto seria pronunciar verde $e^{44}$.

Isso ocorre porque a leitura é uma atividade mais automatizada do que a identificação de $\operatorname{cores}^{45}$. Com um pouco de tempo, todavia, as pessoas saem-se bem na tarefa, nomeando a cor corretamente. Neurologicamente, o que se dá aqui é um conflito interno, com parte dos neurônios empenhada na leitura e parte empenhada na identificação da cor. O papel do controle cognitivo é exatamente orquestrar essas duas atividades e conferir respostas corretas. Essa função cabe a circuitos neurais localizados no sistema 2 (dorso lateral, ou DLPFC), nosso sistema reflexivo, lento e preciso ${ }^{46}$.

Após Cohen, Greene comprova que o dilema do bonde atua de forma semelhante ao experimento acima, provocando respostas conflitantes em nossa mente ${ }^{47}$. Estudos que monitoram o cérebro de indivíduos respondendo à pergunta do dilema do bonde nas duas versões demonstram que a primeira provoca uma atividade maior no sistema 1 (ventro medial, ou VMPFC) e na amígdala (estrutura responsável pela atenção e vigilância a perigos).

Ou seja, por algum motivo, no switch case, a atividade no sistema 1 é menos intensa do que no footbridge case, de modo que, agora, o sistema 2, responsável pelo controle cognitivo, é capaz de conter o impulso instintivo do sistema 1, fazendo prevalecer uma regra utilitária de julgamento capaz de salvar um número maior de vidas ${ }^{48}$. Essa seria a razão pela qual um grande número de pessoas aprova a conduta do agente no switch case $(87 \%)^{49}$, o que não ocorre no footbridge case (apenas $31 \%$ dos participantes, em média, aprovam o empurrão) ${ }^{50}$.

42 GREENE, Joshua D. Moral Tribes: Emotion, Reason and the Gap Between Us and Them. New York: Penguin Books, 2013, p. 117. Mesmo para quem julga a segunda conduta como moralmente errada, muito provavelmente ela parecerá menos errada do que a primeira.

43 COHEN, Jonathan D.; MILLER, Earl K. An Integrative Theory of Prefrontal Cortex Function. Annual Review of Neuroscience, v. 24, p. 167-202, 2001. "The prefrontal cortex has long been suspected to play an important role in cognitive control, in the ability to orchestrate thought and action in accordance with internal goals. Its neural basis, however, has remained a mystery. Here, we propose that cognitive control stems from the active maintenance of patterns of activity in the prefrontal cortex that represent goals and the means to achieve them. They provide bias signals to other brain structures whose net effect is to guide the flow of activity along neural pathways that establish the proper mappings between inputs, internal states, and outputs needed to perform a given task." (p. 167).

44 COHEN, Jonathan D.; MILLER, Earl K. An Integrative Theory of Prefrontal Cortex Function. Annual Review of Neuroscience, v. 24, p. 167-202, 2001. p. 170.

45 COHEN, Jonathan D.; MILLER, Earl K. An Integrative Theory of Prefrontal Cortex Function. Annual Review of Neuroscience, v. 24, p. 167-202, 2001. p. 170.

46 GREENE, Joshua D. Moral Tribes: Emotion, Reason and the Gap Between Us and Them. New York: Penguin Books, 2013. p. 120.

47 GREENE, Joshua D. Moral Tribes: Emotion, Reason and the Gap Between Us and Them. New York: Penguin Books, 2013. p. 121.

48 GREENE, Joshua D. Moral Tribes: Emotion, Reason and the Gap Between Us and Them. New York: Penguin Books, 2013. p. 121.

49 GREENE, Joshua D. Moral Tribes: Emotion, Reason and the Gap Between Us and Them. New York: Penguin Books, 2013. p. 220.

50 GREENE, Joshua D. Moral Tribes: Emotion, Reason and the Gap Between Us and Them. New York: Penguin Books, 2013. p. 215. 
Múltiplos experimentos com diversas versões desses e de outros dilemas demonstram que dilemas "pessoais" como o footbridge case provocam maior atividade na amigdala e no VMPFC, enquanto que dilemas "menos pessoais", como o switch case, ativam essas estruturas com intensidade inferior.

A figura abaixo corresponde à identificação das três estruturas cerebrais envolvidas nos julgamentos morais, compondo o sistema 1 (amigdala e VMPFC) e o sistema 2 (DLPFC):

Figura 3 - Estruturas cerebrais envolvidas nos julgamentos morais ${ }^{51}$

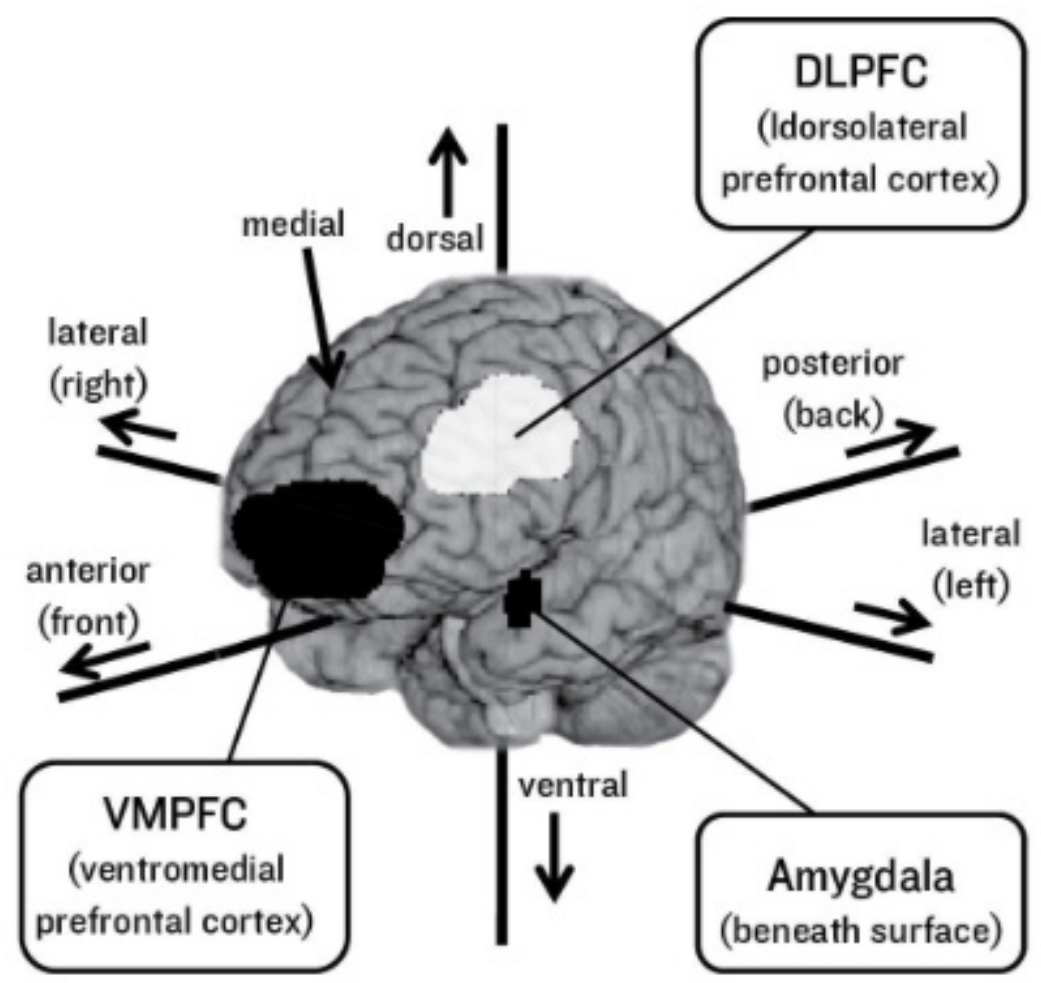

Interessante estudo aplicou o dilema em sua versão original (footbridge case) a pacientes com demência frontotemporal, ou seja, com deficiência específica no sistema 1, semelhante àquela que acometia Phineas Gage ${ }^{52}$, por nós já estudada. Enquanto no grupo de controle apenas 20\% das pessoas aprovaram a ação de empurrar o funcionário da ponte, a aprovação entre os pacientes com deficiência frontotemporal foi de $80 \%{ }^{53}$.

De outro lado, pesquisas foram desenhadas para medir o resultado das respostas aos dilemas quando o sistema 2 é desativado ou amortecido. Para tanto, utilizaram-se duas técnicas: a primeira consistiu em realizar o teste dos dilemas enquanto o sistema 2 é ocupado com atividades cognitivas demandantes ${ }^{54}$ (como realizar

51 GREENE, Joshua D. Moral Tribes: Emotion, Reason and the Gap Between Us and Them. New York: Penguin Books, 2013. p. 123.

52 MENDEZ, Mário F.; ANDERSON, E.; SHAPIRA, J. S. An Investigation of Moral Judgement in Frontotemporal Dementia. Cognitive Behavioral Neurology, v. 18, n. 4, p. 193-197, dez. 2005.

53 A importância desse estudo foi a de dar um passo adiante do inicialmente oferecido pelas imagens de ultrassonografia. Enquanto o ultrassom mostrava evidente correlação entre julgamentos morais e o dual-process mode, o experimento de Mendez e colegas, ao expor paciente com sistema 1 defeituoso, evidenciou causalidade entre a resposta repulsiva aos dilemas pessoais e as estruturas do sistema 1. Pesquisas mais recentes confirmaram o mesmo padrão de resultado, mesmo quando os pacientes são levados a escolher entre salvar membros da própria família em número menor em prol de estranhos em número maior. (THOMAS, Bradley C.; CROFT, Katie E.; TRANEL, Daniel. Harming Kin to Save Strangers: Further Evidence for Abnormally Utilitarian Moral Judgments after Ventromedial Prefrontal Damage. Journal of Cognitive Neuroscience, v. 23, n. 9, p. 2.186-2.196, set. 2011). Ainda sobre o tema, com resultados semelhantes: MORETTO, Giovanna; LÀDAVAS, Elisabetta, MATTIOLI, Flavia; DI PELLEGRINO, Giuseppe. A psychophysiological investigation of moral judgment after ventromedial prefrontal damage. Journal of Cognitive Neuroscience, v. 22, n. 8, p. 1.888-1.899, 2009. Como veremos mais à frente, uma das leis da cooperação é que ela exista entre membros da família, fato que ocorre inclusive entre animais.

54 GREENE, Joshua D.; MORELLI, Sylvia A.; LOWENBERG, Kelly; NYSTROM, Leigh E., COHEN, Jonathan D. Cognitive 
uma operação matemática ou memorizar um número); a segunda implicou aplicar os testes com curto lapso para deliberação, comparando os resultados obtidos com as respostas dadas com maior tempo para reflexão do participante ${ }^{55}$. Em ambos os casos, o coeficiente de respostas utilitaristas caiu bastante.

Demonstrada a relação entre as repostas aos dilemas e o funcionamento das estruturas que correspondem aos dois sistemas que operam no cérebro (dual processo brain), é necessário entender o porquê de esses sistemas operarem com intensidades diferentes nas duas versões do dilema. Trocando em miúdos, é preciso entender a razão de nós aceitarmos o trade-off de uma vida pela salvação de cinco no 'switch case', mas não no 'footbridge case'.

Duas outras versões do dilema comprovam a influência da pessoalidade do enredo no nível de participação do sistema 1 (instintos) quando das respostas. Trata-se do remote footbridge case e do footbridge switch case, hipóteses muito semelhantes à original, com a única diferença de que, em vez de empurrar o funcionário, a pessoa aciona uma alavanca que abre a ponte fazendo-o cair, provocando sua morte e salvando as cinco outras vidas. No remote footbridge case, o agente e a alavanca estão distantes dos trilhos, enquanto no footbridge switch case eles encontram-se sobre a ponte, próximos ao funcionário. As representações gráficas de ambas as versões estão representadas nas figuras 4 e 5 .

Figura 4 - Remote footbridge $\operatorname{case}^{56}$

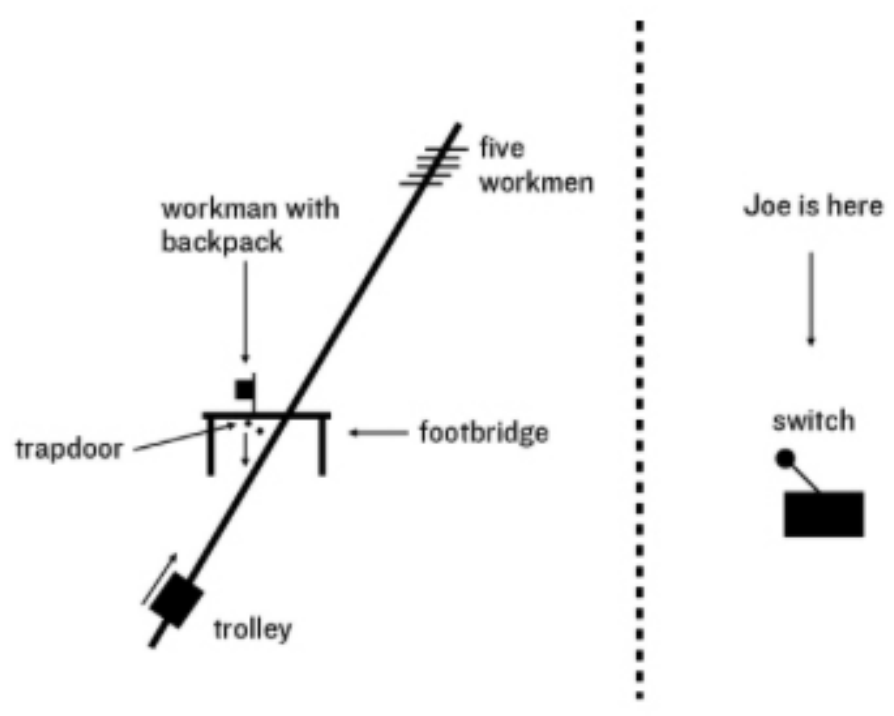

Load Selectively Interferes with Utilitarian Moral Judgment. Journal of Cognitive Neuroscience, v. 22, n. 8, p. 1.888-1.899, jun. 2008.

55 Obviamente, em grupos diferentes, com todos os controles envolvidos. (SUTER, Renata S.; HERTWIG, Ralph. Time and Moral Judgment. Cognition, v. 119, n. 3, p. 454-458, jun. 2011).

56 GREENE, Joshua D. Moral Tribes: Emotion, Reason and the Gap Between Us and Them. New York: Penguin Books, 2013. p. 214. 
Figura 5 - Footbridge switch case $e^{57}$

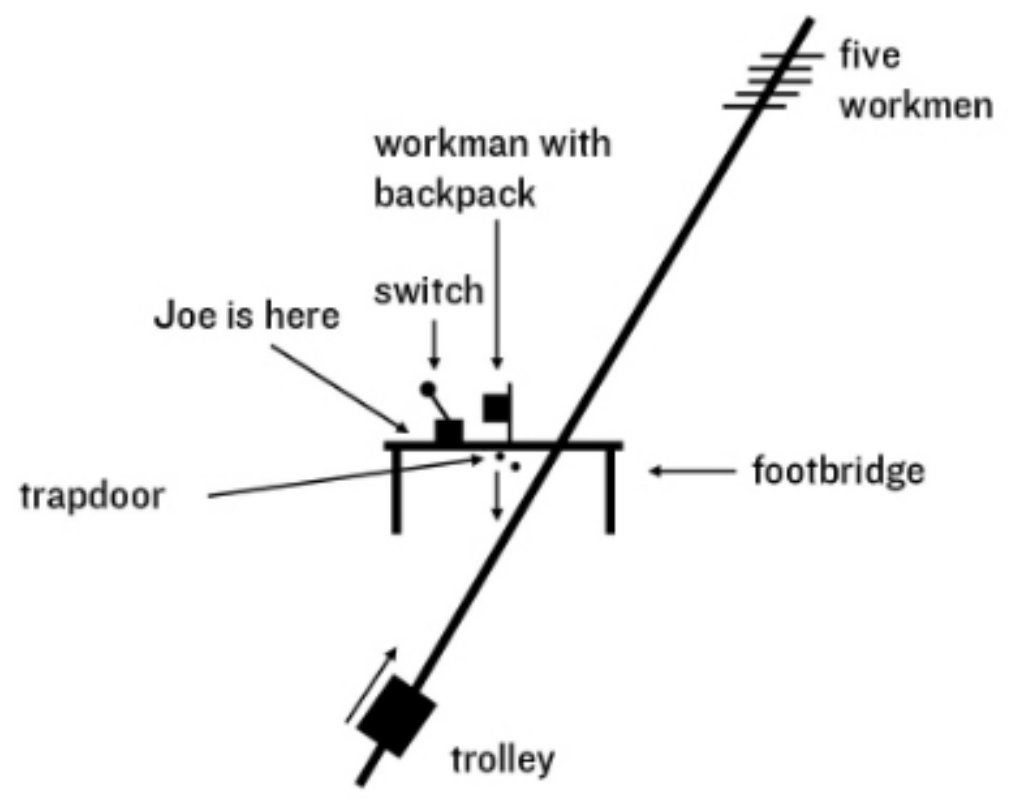

O estudo submeteu o mesmo grupo de pessoas às três versões do footbridge case. Enquanto na versão original (a do empurrão) a aprovação do resultado utilitarista foi de apenas 31\%, nessas novas versões, a aprovação foi de $63 \%$ e $59 \%$, respectivamente.

Note-se que a segunda versão se caracteriza por duas diferenças em relação à original: (i) o agente está mais distante da vítima; (ii) o agente não toca o corpo da vítima. Já a terceira versão diferencia-se da primeira apenas pela falta de toque no corpo da vítima (já que a alavanca está sobre a ponte, próxima do funcionário). Importa, então, saber qual das duas diferenças realmente impactou o resultado.

A resposta está no contato pessoa ${ }^{58}$. Sem o contato pessoal, os exemplos se parecem muito com o switch case (que tinha $87 \%$ de aprovação). A única diferença é o fato de que, no footbridge switch case (59\% de aprovação), a alavanca (e, logo, o agente) está muito mais próxima do funcionário do que no switch case e no remote footbridge case (63\% de aprovação), hipóteses em que o agente e a alavanca estão fora da ponte e, logo, mais distantes do funcionário que servirá de obstáculo.

Não há diferenças estatisticamente significantes de aprovação entre o switch case e o remote footbridge case, mas a diferença percentual entre esses enredos e aquele que inclui o contato pessoal (footbridge case, com apenas $31 \%$ de aprovação) é enorme, indicando que não é a alteração de distância que impacta o sistema 1, mas sim o contato pessoal ${ }^{59}$.

Ocorre que, na versão original do footbridge case, mais do que o contato pessoal, o que ocorre é realmente um empurrão, ou seja, a aplicaşão de força muscular contra a vítima. Assim, é preciso saber em que medida importa tocar ou aplicar força muscular sem tocar o funcionário.

Conduziu-se, então, outro estudo com uma nova alteração da versão original. Aqui, o agente não toca no funcionário, mas empurra-o com um bastão. A figura 6 representa graficamente a situação:

57 GREENE, Joshua D. Moral Tribes: Emotion, Reason and the Gap Between Us and Them. New York: Penguin Books, 2013. p. 215.

58 CUSHMAN, F.; YOUNG, L.; HAUSER, M. The Role of Conscious Reasoning and Intuition in Moral Judgment: Testing Three Principles of Harm. Psychology Science, v. 17, n. 12, p. 1.082-1.089. 2006.

59 GREENE, Joshua D. Moral Tribes: Emotion, Reason and the Gap Between Us and Them. New York: Penguin Books, 2013. p. 216. 
Figura 6 - Footbridge pole dilemma ${ }^{60}$

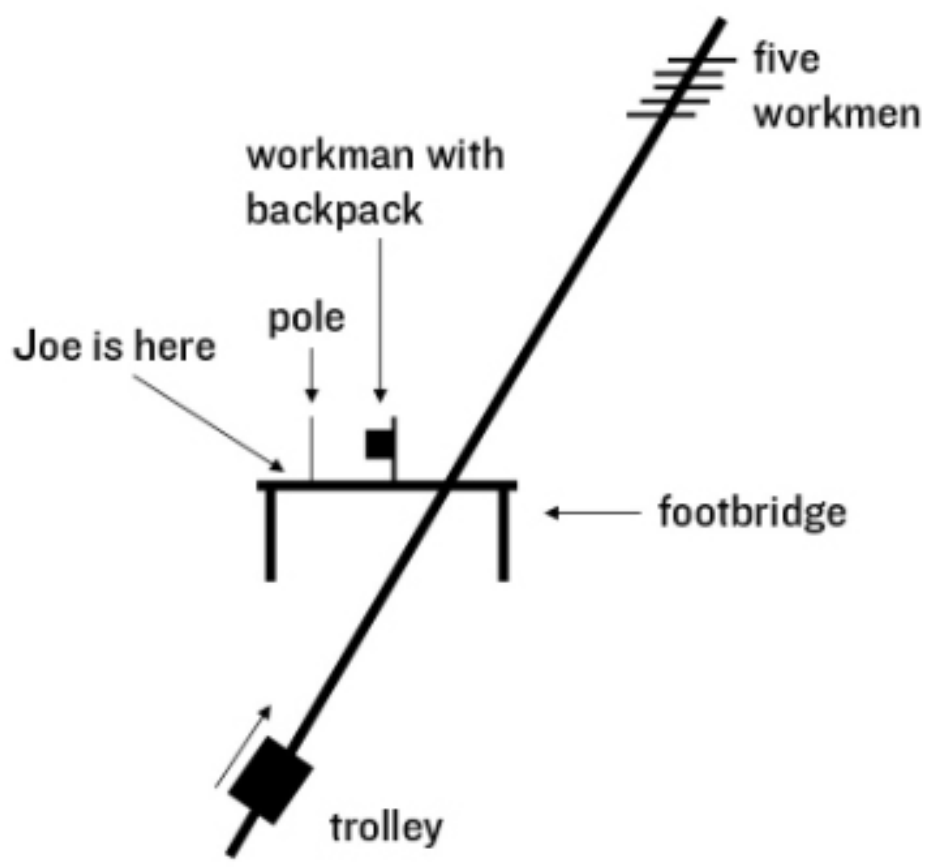

Nesse caso, o percentual de aprovação foi semelhante ao da versão tradicional, ou seja, o relevante para o sistema 1, mais do que o toque, é a aplicação de força pessoal sobre uma outra pessoa, ainda que por intermédio de um objeto.

Há uma abordagem do dilema que procura relacioná-lo à máxima kantiana já referida de que as pessoas não devem ser tratadas como meio, mas sim como o fim de qualquer atividade ${ }^{61}$.

$\mathrm{Na}$ versão original do footbridge case, a pessoa é realmente utilizada como um meio para parar o bonde, mas, no switch case, a morte do funcionário é um efeito colateral da tentativa de salvar cinco vidas. Explicando melhor: ao empurrar o funcionário da ponte, o agente usa o corpo do funcionário como um obstáculo que impede o bonde de matar os cinco operários. Já no switch case, as cinco vidas são salvas pelo desvio do curso do bonde, acionado pela alavanca. A morte do funcionário é um efeito colateral desse desvio, porque ele está acidentalmente sobre os trilhos laterais. Não é, portanto, utilizado como meio para parar o bonde ${ }^{62}$.

Para medir a sensibilidade do sistema 1 em relação a essa distinção (meio versus efeito colateral), estudou-se uma nova versão do dilema, chamada de obstacle collide case. Nesse novo enredo, o curso do bonde pode ser alterado movendo-se uma alavanca (como no switch case). A alavanca, o agente e o funcionário estão sobre a ponte (como no footbridge switch case). A diferença agora é que a ponte está sobre o trilho lateral, o funcionário encontra-se entre o agente e a alavanca, e a única forma de o agente alcançar a alavanca é empurrando o funcionário e derrubando-o sobre os trilhos. A figura 7 representa a nova situação:

60 GREENE, Joshua D. Moral Tribes: Emotion, Reason and the Gap Between Us and Them. New York: Penguin Books, 201. p. 216.

61 Antes de Kant, Tomás de Aquino trata do mesmo tema, com a mesma opinião, sob outra perspectiva. Aquino cria a doutrina do duplo efeito, segundo a qual é moralmente permitido que uma conduta cause um mal, inclusive a morte de alguém, como efeito colateral da promoção de um bem maior. (MCINTYRE, Alison. Doctrine of Double Effect. In: ZALTA, Edward N. (Ed.). The Stanford Encyclopedia of Philosophy, inverno 2014. Disponível em: < https://plato.stanford.edu/archives/win2014/entries/double-effect>. Acesso em: 16 fev. 2018).

62 Para visualizarmos essa ideia, basta retirar mentalmente o funcionário do trilho nas duas hipóteses. No footbridge case, o bonde seguiria em frente e atropelaria os cinco trabalhadores. No switch case, os cinco trabalhadores seria salvos. 
Figura 7 - Obstacle collide dilemma ${ }^{63}$

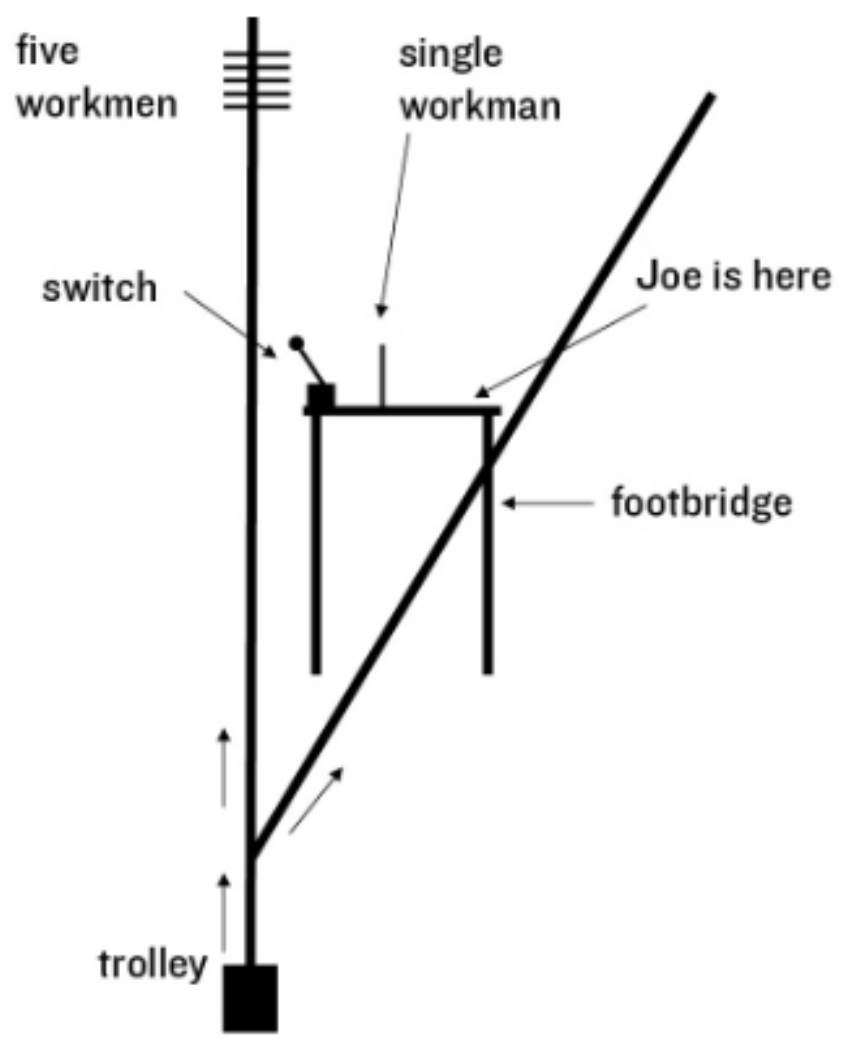

Nessa versão, assim como na original, há pessoalidade na ação, mas o funcionário não é utilizado como meio. Trata-se de um misto entre o footbridge case (pessoalidade) e o switch case (colateralidade). O percentual de aprovação aqui foi de $81 \%$, algo muito próximo da aprovação do switch case (87\%), demonstrando que o sistema 1 de fato é altamente sensível à diferença entre meio/ efeito colateral apresentada ${ }^{64}$.

O resultado parece demonstrar que nossa intuição aponta como imoral o ato de ferir alguém como meio, mas aprova a moralidade de fazê-lo como efeito colateral de um ato de salvamento de um número maior de pessoas.

Todavia, em duas das versões aqui apresentadas (remote footbridge case e footbridge switch case), as pessoas aprovaram o ato de utilizar o funcionário como meio para parar o bonde, ainda que com índices de aprovação inferiores (63\% e 59\%, respectivamente). Esse é um dado intrigante e que coloca em dúvida nosso apreço intuitivo em relação ao imperativo categórico kantiano.

Uma outra versão do dilema traz ainda mais controvérsia à discussão. Trata-se do loop case $e^{65}$. Essa hipótese é quase idêntica ao switch case original, com a diferença de que o acionamento da alavanca desvia o bonde para um trilho que segue paralelo ao primeiro, mas faz uma curva antes de voltar à trilha original, onde estão os operários. Nessa curva encontra-se o funcionário, que acaba morrendo e impedindo que o bonde volte ao trilho original onde estão os cinco operários, que acabam sendo salvos. A hipótese está representada na figura 8:

63 GREENE, Joshua D. Moral Tribes: Emotion, Reason and the Gap Between Us and Them. New York: Penguin Books, 2013. p. 219.

64 GREENE, Joshua D. Moral Tribes: Emotion, Reason and the Gap Between Us and Them. New York: Penguin Books, 2013. p. 219-220.

65 A intrigante versão foi novamente criada por Thomson, anos depois do paper original. (THOMSON, Judith. The Trolley Problem. The Yale Law Journal, v. 94, n. 6, p. 1.395-1.415, maio, 1985. Especificamente p. 1.402-1.403). 
Figura 8 - Loop case $e^{66}$

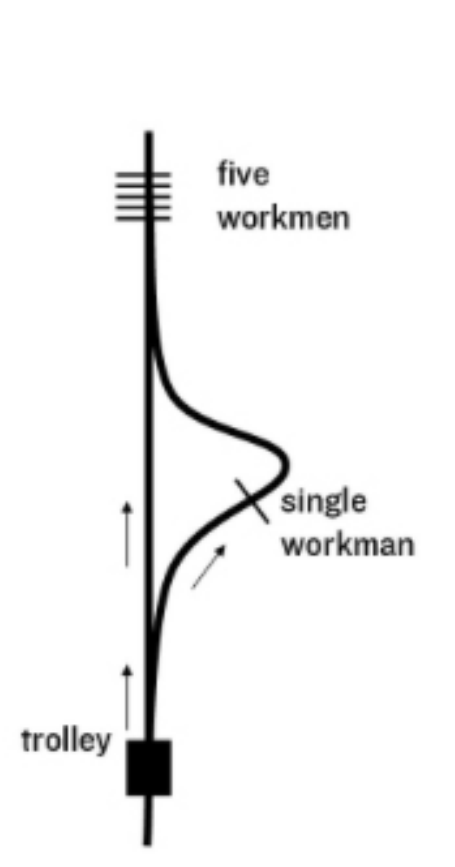

Joe is here

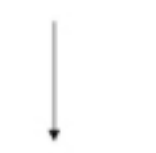

switch

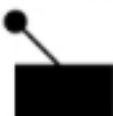

Pela figura, pode-se notar que a diferença para o switch case original é o fato de o funcionário ser utilizado como meio para parar o bonde. Isso porque a alavanca desvia o curso do bonde apenas momentaneamente e, não fosse o funcionário, ele voltaria ao curso original, matando os cinco operários. Mesmo assim, 81\% dos participantes aprovam a conduta do agente nesse caso, o que parece lançar ainda mais dúvidas sobre a relação intuitiva da nossa mente com o imperativo categórico kantiano em questão ${ }^{67}$.

Após a análise de todas essas versões em conjunto, podemos identificar dois fatores que realmente alteram o julgamento das pessoas: (i) a utiliz̧ação de força pessoal (empurrar versus mover uma alavanca); (ii) a utilização de uma pessoa como meio para parar o bonde (morte como decorrência direta versus morte como decorrência colateral).

Todavia, a mesma análise mostra que a influência desses dois fatores é inconsistente. A força pessoal pode ou não causar reprovação (footbridge pole versus obstacle collide, respectivamente). Da mesma forma, a utilização da pessoa como meio pode importar ou não (footbridge case versus loop case $)^{68}$.

Green conclui que o que realmente modifica o julgamento pela ativação do sistema 1 é a interação entre os dois fatores, ou seja, a aplicação de força pessoal e a utilização da pessoa como meio. ${ }^{69}$ A utilização de força pessoal que mata o funcionário como efeito colateral não é reprovável (81\% de aprovação para o obstacle collide), bem como a utilização do funcionário como meio sem utilização de força pessoal (81\% de aprovação para o loop case). Todavia, quando combinados os dois fatores, a reprovação é substancial (apenas 31\% de aprovação

66 GREENE, Joshua D. Moral Tribes: Emotion, Reason and the Gap Between Us and Them. New York: Penguin Books, 2013. p. 220.

67 Há outras variações do dilema cujos resultados levantam a mesma questão. (GREENE, Joshua D. GREENE, Joshua D. Moral Tribes: Emotion, Reason and the Gap Between Us and Them. New York: Penguin Books, 2013. p. 221).

68 Em um experimento, o footbridge case e o switch case foram aplicados para filósofos com $\mathrm{PhD}$, divididos em dois grupos. No grupo 1, o footbridge case era apresentado antes do switch case. No grupo 2, a apresentação era invertida. Descobriu-se que, quando o footbridge case era apresentado após o switch case, o percentual de aprovação moral subia à razão de $50 \%$. Em outras palavras, o percentual de aprovação do footbridge case no grupo 2 foi $50 \%$ superior ao percentual de aprovação do grupo 1. (SCHWITZGEBEL, Eric; CUSHMAN, Fiery. Expertise in Moral Reasoning? Order Effects on Moral Judgment in Professional Philosophers and NonPhilosophers. Mind \& Language, v. 27, p. 135-153, 2012).

69 GREENE, Joshua D. Moral Tribes: Emotion, Reason and the Gap Between Us and Them. New York: Penguin Books, 2013. p. 222. 
para o footbridge case e 33\% para o footbridge pole).

O que se conclui desses estudos é que a diferença de julgamentos para situações com resultados idênticos (trade-off entre a morte de um funcionário e a salvação de cinco operários) é causada pelo nível de atividade do sistema 1, ou seja, pela nossa intuição/instinto moral. Ao que tudo indica, todavia, o sistema é falho, porque, conquanto não haja qualquer diferença moralmente relevante entre empurrar (footbridge) ou mover uma manivela (remote footbridge) e derrubar alguém de uma ponte com o intuito de parar um bonde, o sistema 1 responde de modo diferente à duas situações, reprovando um caso e aprovando o outro.

Se é assim, qual seria a explicação para o enorme corpo filosófico que rejeita a ideia de utilizar pessoas como meio para qualquer objetivo? Como explicar as diferenças valorativas entre matar alguém como meio ou como efeito colateral nos casos em que o agente sabe de antemão que a morte vai acontecer? Porque somente se reprova o primeiro caso, se o resultado e as intenções são exatamente as mesmas (salvar mais pessoas, sabendo que dessa conduta decorrerá a morte de alguém)?

A hipótese sustentada é no sentido de que as teorias são apenas racionalizações dos julgamentos intuitivo ${ }^{70} A$ intuição viria primeiro (sistema 1), e seria racionalizada pelo sistema 2. Em outras palavras, o sistema reflexivo atuaria ancorado nos instintos, organizando-os de forma imperfeita e inconsistente ${ }^{71}$. Não é o imperativo categórico kantiano que justifica os instintos, mas os instintos que justificam o imperativo categórico ${ }^{72}$.

Aceita essa hipótese, resta ainda uma pergunta: de onde vêm esses instintos?

\section{A raiz biológica dos instintos transformada em imperativo categórico Kantiano (a TEORIA DA MIOPIA MODULAR)}

A Teoria da Miopia Modular de Greene é fruto de uma reflexão sobre os julgamentos morais produzidos pelo dual-process system, fundada na forma como nossa mente representa ações. Em resumo, a hipótese defendida é a de que nós temos um subsistema cognitivo que monitora nossos planos comportamentais e aciona um alarme emocional sempre que divisamos a possibilidade de ferir fisicamente alguém. A hipótese segue para sugerir que esse sistema de alarme é mípe, porque simplesmente não detecta efeitos nocivos visualizados pelo agente, atentando, apenas, para aqueles planejados como meio para atingimento do objetivo final ${ }^{73}$.

Esse sistema, ou módulo, é responsável por alertar-nos contra a prática de atos básicos de violência. Suas limitações não atingem a cognição dos efeitos colaterais, mas sim as emoções que dela decorreriam. Em outras palavras, para os efeitos nocivos colaterais, o sistema 2 funciona perfeitamente, mas o sistema 1 não ${ }^{74}$.

\footnotetext{
70 As pessoas ao redor do mundo, independentemente do nível intelectual ou cultural, intuem a máxima kantiana, sem saber de que se trata de uma doutrina. Nesse sentido: HAUSER, Marc; CUSHMAN, Fiery; YOUNG, Liane; JIN, R. Kang-Xing; MIKHAIL, John. A Dissociation Between Moral Judgments and Justifications. Mind \& Language, v. 22, n. 1, p. 1-21, fev. 2007: “[...] a majority of subjects failed to provide justifications that could account for their judgments. These results indicate that the principle of the double effect may be operative in our moral judgments but not open to conscious introspection." (p. 1).

71 KAHNEMAN, Daniel. Thinking: fast and slow. New York: Farrar, Straus and Giroux, 2011. [Kindle], location 2.080.

72 CUSHMAN, F.; GREENE, J. D. The Philosopher in the Theater. In: MIKULINCER, M.; SHAVER, P. R. (Eds.). Social Psychology of Morality: The Origins of Good and Evil. APA, 2011. Disponível em: <http://cushmanlab.fas.harvard.edu/docs/ cushman\&greene_2011b.pdf > . Acesso em: 16 fev. 2018. Os autores afirmam que, da mesma forma que teorias científicas tendem a refletir as estruturas do mundo concreto, as teorias filosóficas tendem a refletir as estruturas da mente (cérebro). (p. 6). Lembramos ainda a pesquisa em que o dilema do bonde foi aplicado a doutores em filosofia. A mera ordem de apresentação dos problemas alterou o resultado. (SCHWITZGEBEL, Eric; CUSHMAN, Fiery. Expertise in Moral Reasoning? Order Effects on Moral Judgment in Professional Philosophers and Non-Philosophers. Mind \& Language, v. 27, p. 135-153, 2012).

73 GREENE, Joshua D. Moral Tribes: Emotion, Reason and the Gap Between Us and Them. New York: Penguin Books, 2013. p. 224.

74 GREENE, Joshua D. Moral Tribes: Emotion, Reason and the Gap Between Us and Them. New York: Penguin Books, 2013. p. 224. Também sobre o tema: BLAIR, R. J. R. A Cognitive Developmental Approach to Morality: Investigating the Psychopath. Cognition, v. 57, p. 1-29, 1995.
} 
Esse sistema cognitivo dual existe por razões evolutivas já reveladas pela biologia e pela neurociência. Em algum momento de sua história natural/evolutiva, o homo sapiens desenvolveu um importante diferencial competitivo em relação às outras espécies: a capacidade de raciocinar e planejar suas ações (sistema 2$)^{75}$. Com isso, foi possível, por exemplo, criar estratégias mais elaboradas de sobrevivência, estabelecer objetivos de longo prazo e construir ferramentas que tornaram o homem/mulher mais forte que as demais espécies.

O custo desse sistema, porém, é a capacidade de premeditação de violência contra membros da própria espécie. Sem o sistema 2, a violência é, apenas, um impulso. Com esse novo sistema, ela pode ser escalada para níveis capazes de ameaçar toda a coletividade (grupo ou tribo). Capacidade cooperativa é um diferencial evolutivo para qualquer espécie, dentro de tribos ou famílias, os atos de violência são normalmente punidos com violência (vingança), colocando em risco a estabilidade do grupo e abrindo a possibilidade de invasão e domínio por outras tribos ou espécies ${ }^{76}$.

Exatamente para evitar essa violência desenfreada, desenvolvemos esse sistema de alerta. Esse inspetor de planejamento e ação não objeta todo e qualquer ato de violência, mas apenas aqueles que colocam em xeque a cooperação como diferencial evolutivo. Assim, o sistema desliga, por exemplo, quando praticamos atos violentos para nos defender, ou para atacar um inimigo ${ }^{77}$.

É preciso entender, todavia, por que esse sistema é míope para os efeitos nocivos colaterais às nossas ações. Em verdade, ambos os sistemas são, de certa forma, incompletos. O sistema 2, por exemplo, é egoísta ao extremo no planejamento de suas ações, racional quanto às perdas e ganhos de determinada situação e cego para potenciais perigos daí advindos, principalmente no longo prazo, uma vez que a reciprocidade não é facilmente verificável (cognoscível) no curto prazo (como vimos, os pacientes de Antonio Damasio apresentavam sérios problemas de tomada de decisão).

Já o sistema 1 é automático e rápido. Para isso, ele trabalha com atalhos, heurísticas e pressuposições. Confia em pistas imperfeitamente relacionadas àquilo que deve detectar. Funciona, por exemplo, como um alarme com sensores infravermelhos, instalado para a segurança dos moradores de uma casa, do qual espera-se um disparo capaz apontar a presença de um criminoso invasor da propriedade. Todavia, se um gato de rua atravessar seu raio de ação, o alarme disparará, alertando (e assustando) os moradores sem motivo relevante. Assim, o sistema 1 oferece de maneira rápida, eficiente e imprecisa, alarmes e avisos para os potenciais perigos das ações antevistas pelo sistema 2. Mas também dispara em razão de eventos apenas aparentemente perigosos.

A prova do funcionamento desse sistema decorre de experimentos desenhados para simular sinais de violência para o sistema $1 \mathrm{e}$, ao mesmo tempo, informar o sistema 2 da inexistência de qualquer violência real. Se o sistema modular realmente existe e funciona de forma automática, então, ele deve ser acionado mesmo quando estamos conscientes de que o ato violento por nós praticado é, apenas, uma simulação.

Para entender melhor o funcionamento do sistema de alerta, um interessante experimento foi conduzido por Cushman, Mendes e colegas ${ }^{78}$. Nele, os participantes praticavam atos de violência simulada, conscientes dessa circunstância. Eles foram convidados a, por exemplo, esmagar bonecos, martelar a perna falsa de uma pessoa e apontar uma arma de brinquedo para alguém.

Sempre que o ato de violência simulada era praticado, o agente experimentava uma forte constrição no

75 Como vimos, o sistema 2 é uma exclusividade do bomo sapiens. (FRANKISH, Keith. Dual-Process and Dual-System Theories of Reasoning. Philosophy Compass, v. 5, n. 10, p. 914-926, 2010. p. 914).

76 Sobre o tema: NOWAK, Martin A. Five Rules for the Evolution of Cooperation. Science, v. 314, n. 5.805, p. 1.560-1.563, 8 dez. 2006. Disponível em: <https://www.ncbi.nlm.nih.gov/pmc/articles/PMC3279745>. Acesso em: 16 fev. 2018.

77 GREENE, Joshua D. Moral Tribes: Emotion, Reason and the Gap Between Us and Them. New York: Penguin Books, 2013. p. 226.

78 CUSHMAN, F.; GAFFEY, A.; GRAY, K.; MENDES, W. B. Simulating Murder: The Aversion to Harmful Action. Emotion, v. 12, n 1, p. 2-7, 2012. Disponível em: <https://cushmanlab.fas.harvard.edu/docs/cushman_gray_gaffey\&mendes_2012.pdf>. Acesso em: 30 jul. 2017. 
sistema vascular periférico (uma espécie de calafrio). Essa sensação não se desencadeava com a mesma intensidade quando o participante, apenas, assistia ao ato simulado ou quando o praticava contra objetos não assemelhados a humanos (por exemplo, quando martelavam um prego, em vez da cabeça de uma boneca) ${ }^{79}$.

Esses resultados indicam que o sistema 1 é acionado automaticamente mesmo com base em um sinal cuja falsidade seja conhecida do agente, desde que para frear atos pessoais de violência ${ }^{80}$.

Se, por um lado, o sistema dispara na presença de falsos sinais de violência, por que ele não é acionado para atos que possuem consequências danosas reais colaterais? Em outras palavras, por que o sistema é cego em relação aos efeitos colaterais?

A resposta está no modo como nosso cérebro representa ações - em forma de diversas cadeias causais - e na incapacidade de processamento simultâneo de todas elas para a produção de respostas rápidas.

Segundo John Mikhail, o cérebro humano representa ações em termos de cadeias causais planificadas, voltadas ao alcance de determinado objetivo ${ }^{81}$. A cadeia inicial consiste em uma sequência de eventos causais necessários ao atingimento de uma específica finalidade. Por exemplo, no switch case, a cadeia é composta pelo movimento muscular que move as mãos do agente, causando o acionamento da alavanca, a subsequente alteração dos trilhos e o desvio do bonde, que termina por resultar na salvação dos cinco operários. Já a morte do funcionário no trilho secundário não compõe essa cadeia causal principal, mas sim uma cadeia adjacente (colateral).

Já no footbridge case, a cadeia causal principal é a seguinte: o movimento muscular do agente move suas mãos para empurrar o funcionário, causando sua queda e a parada do bonde, implicando a morte do funcionário e a preservação das cinco vidas. Não há qualquer cadeia causal colateral (salvo o sofrimento da família e dos amigos do funcionário morto).

Qual a diferença fundamental entre as cadeias causais principais nos dois casos? É o fato de que a morte do agente somente a compõe no segundo caso (footbridge case), não no primeiro. No switch case, a morte não é detectada pelo sistema modular porque ele é desenhado apenas para antecipar automaticamente os efeitos diretos, não os colaterais. Em outras palavras, o sistema automático de alarme percebe apenas causalidades lineares ${ }^{82}$. A figura 9 representa as cadeias causais principais e colaterais dos dois casos:

79 A figura abaixo representa os atos que os participantes foram levados a protagonizar. Os atos da primeira linha geraram contrição vascular periférica bem mais intensa que os da segunda (p. 4).

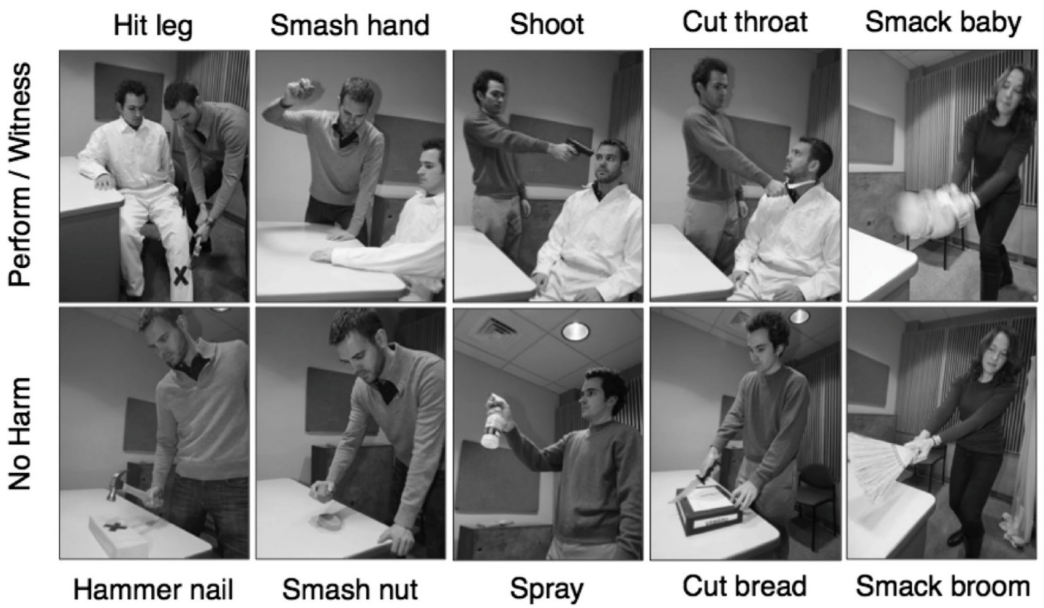

80 CUSHMAN, F.; GAFFEY, A.; GRAY, K.; MENDES, W. B. Simulating Murder: The Aversion to Harmful Action. Emotion, v. 12, n 1, p. 2-7, 2012, p. 5. Disponível em: <https://cushmanlab.fas.harvard.edu/docs/cushman_gray_gaffey\&mendes_2012.pdf>. Acesso em: 30 jul. 2017.

81 MIKHAIL, John. Elements of Moral Cognition: Rawl's Linguistic Analogy and the Cognitive Science of Moral and Legal Judgment. Cambridge, UK: Cambridge University, 2011. [Kindle]. location 3.260.

82 MIKHAIL, John. Elements of Moral Cognition: Rawl's Linguistic Analogy and the Cognitive Science of Moral and Legal Judgment. Cambridge, UK: Cambridge University, 2011. [Kindle]. location 4.233. 
Figura 9 - Cadeias causais, Switch e Footbridge cases $^{83}$

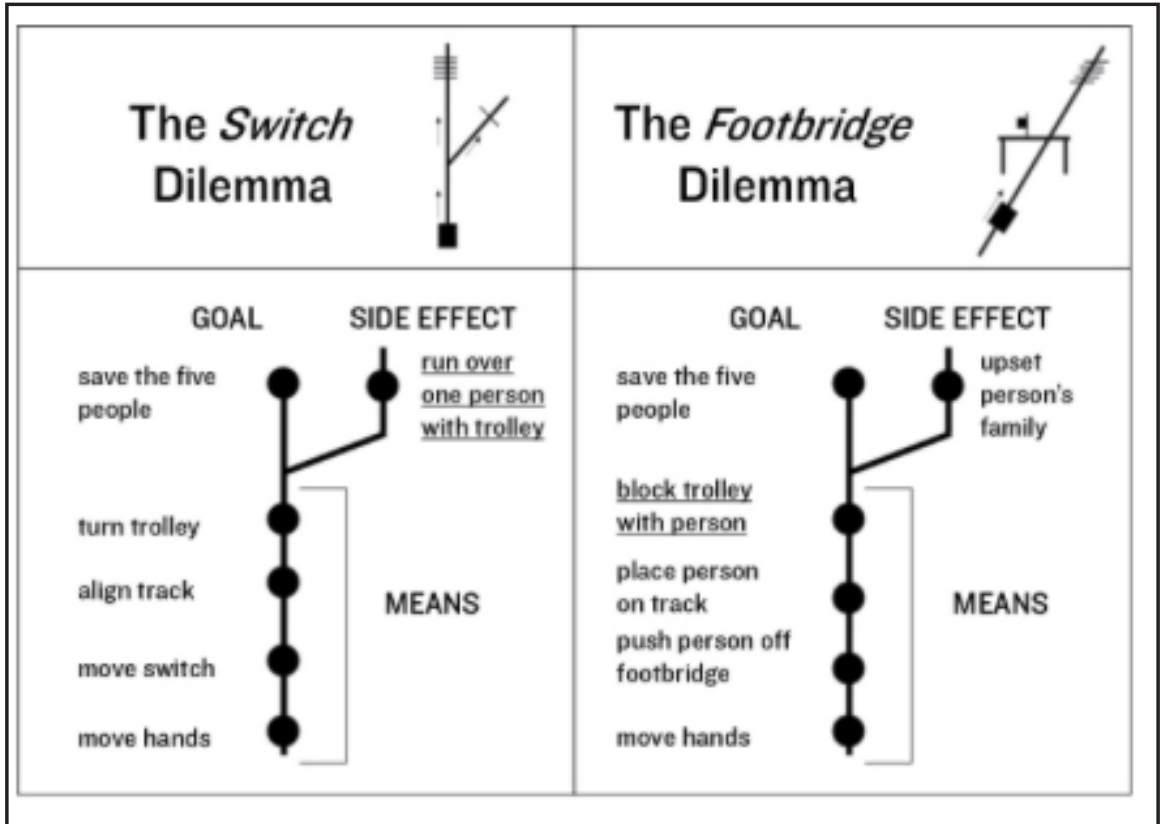

Os efeitos colaterais são conhecidos e previstos pelo agente (o sistema 2 sabe que eles existem). Ele, todavia, não os interpreta como errados, porque o sistema de alarme soa apenas para os eventos componentes da cadeia causal de eventos necessários para atingir o objetivo (trata-se dos eventos que compõem a cadeia causal principal, em linha reta nos dois exemplos da figura acima ${ }^{84}$.

Todavia, como explicar, por essa teoria, o loop case? Lembramos que, nesse caso, a morte do funcionário encontra-se, sem dúvida, na cadeia causal principal, assim composta: o agente movimenta os músculos para mover a mão; a mão move a alavanca; a alavanca altera a trajetória do bonde para o trilho curvo e o bonde atropela o funcionário, matando-o e salvando a vida dos cinco operários ao impedir a volta do veículo ao trilho original.

O problema do loop case é que ele foi desenhado para enganar o sistema $1^{85}$. Conquanto tenhamos consciência de que a morte do funcionário compõe a cadeia causal principal (ele é um meio necessário para salvar as cinco vidas), o sistema 1 enxerga a hipótese de modo semelhante ao switch case, ou seja, ele percebe, apenas, que há um movimento muscular, um acionamento de alavanca e um desvio de trajetória que salva cinco vidas. O sistema, todavia, não soa o alarme para um efeito principal que parece colateral: a morte do agente. O exemplo, assim, engana o sistema 1.

As figuras 10 e 11 representam, respectivamente, a verdadeira cadeia causal principal do loop case e a cadeia causal tal como percebida pelo sistema 1.

83 GREENE, Joshua D. Moral Tribes: Emotion, Reason and the Gap Between Us and Them. New York: Penguin Books, 2013. p. 229.

84 Para que a diferença causal fique clara, basta, mais uma vez, suprimir o funcionário do exemplo. Se ele não existisse, os cinco operários estariam salvos na figura da esquerda, mas morreriam na figura da direita. Logo, na cadeia causal da figura direita, o funcionário é causa direta da preservação de cinco vidas. Em outras palavras, sua morte é o meio utilizado para salvar os operários.

85 GREENE, Joshua D. Moral Tribes: Emotion, Reason and the Gap Between Us and Them. New York: Penguin Books, 2013. p. 234 . 
Figura 10 - Cadeia causal real do loop case $^{86}$

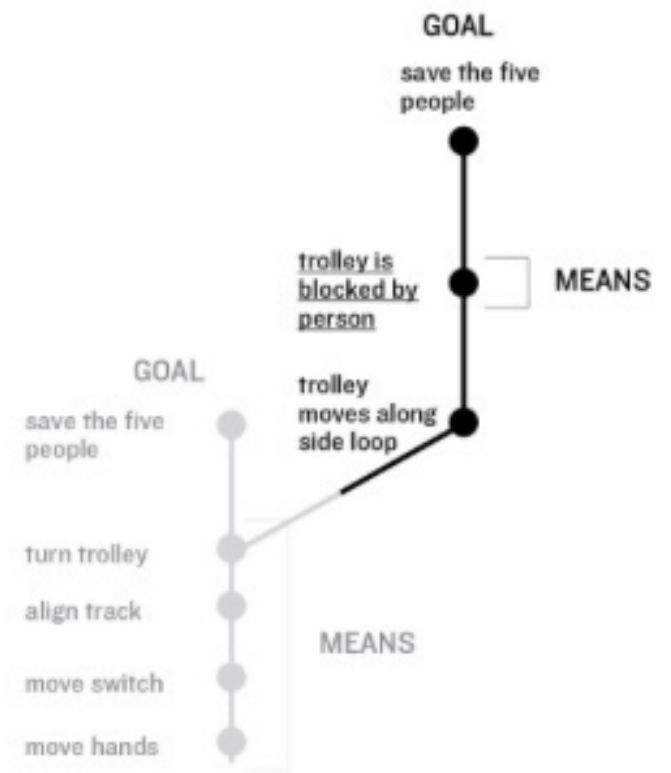

Figura 11 - Cadeia causal do loop case tal como percebida pelo sistema 1 (ignorando o que parece ser um efeito colateral) ${ }^{87}$

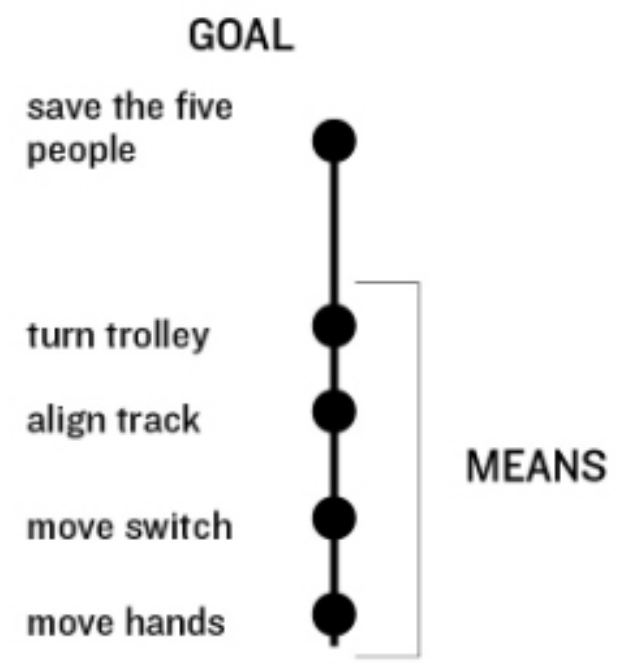

Uma diferença essencial entre o footbridge case e o loop case é, como vimos, o ato de empurrar alguém (força pessoal). É exatamente esse ato que conecta o alerta do sistema 1, trazendo o funcionário para seu radar, de modo que a cadeia causal principal possa ser detectada, ativando o alarme. Isso não ocorre no loop case, hipótese em que a cadeia causal fica dissimulada. Outras linhas de pesquisa demonstram que a mente tende a representar causas em termos de forças, robustecendo relações causais na proporção da concretude de um determinado cenário ${ }^{88}$.

Alguém poderia perguntar o que ocorreria, então, no loop case se, no trilho principal, houvesse, apenas, 1 funcionário, e, no trilho curvo adjacente, estivessem os cinco trabalhadores. Será que a imperfeição do sistema 1 nos faria mover a manivela por não enxergarmos a cadeia causal aparentemente adjacente, induzindo-nos a

86 GREENE, Joshua D. Moral Tribes: Emotion, Reason and the Gap Between Us and Them. New York: Penguin Books, 2013 , p. 233.

87 GREENE, Joshua D. Moral Tribes: Emotion, Reason and the Gap Between Us and Them. New York: Penguin Books, 2013 , p. 232.

88 PINKER, Steven. The Stuff of Thought. Language as a Window Into Human Nature. New York: Penguin, 2007. [Kindle]. p. 1. 
trocar, tragicamente, cinco vidas por apenas uma? A resposta parece-nos negativa. É preciso lembrar que o sistema 2, quando funciona, sempre faz julgamentos utilitários. Ele, sempre, responde positivamente à proposta de trocar uma vida por cinco, mas jamais o contrário. O contrário ocorre, apenas, nos casos em que o sistema 1 é acionado com intensidade, fazendo-nos agir por impulso para refrear um ato de violência que esteja na cadeia causal detectável pelo seu radar, inibindo os cálculos do sistema $2^{89}$.

Em todos os nossos exemplos, o agente sabe, conscientemente, que o trade-off proposto é o de cinco vidas por uma. Não fosse o sistema 1, essa troca sempre seria aceita. De outro lado, com ou sem sistema 1, a troca oposta (uma vida por cinco) jamais ocorreria.

Nesse ponto da nossa explicação, é importante relembrar: o sistema 1, dispositivo fundamental de sobrevivência da espécie humana, funciona de forma rápida e imperfeita. O sistema 2 funciona de forma reflexiva. Mas eles não funcionam isolados. Ao contrário, trabalham integrados ${ }^{90}$. Como ensina Kahneman, julgamentos

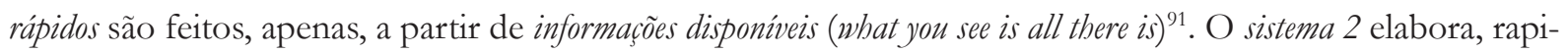
damente, as intuições do sistema 1, sem necessariamente considerar todas as circunstâncias relevantes.

Uma pergunta importante: se o sistema 2 funciona tão bem, porque não somos todos psicopatas (em outras palavras, por que não eliminamos o sistema 1)? Há duas razões para isso. A primeira diz para com as múltiplas funções do sistema 1, capaz de responder rápido e garantir nossa sobrevivência em uma série de situações dinâmicas da vida (seja na selva ao fugir de uma cobra ou na cidade ao pular para evitar um atropelamento surpresa). A segunda decorre da nossa incapacidade de calcular custos e benefícios com a rapidez ou a precisão necessária. Como o percentual de acerto do sistema 1 é bastante razoável ${ }^{92}$, ele leva grande vantagem em relação ao sistema 2 no dia a dia, auxiliando, inclusive, a manutenção da cooperação dentro do grupo, como um diferencial evolutivo.

Mas, ainda que saibamos que o sistema 1 é muito útil, não podemos esquecer que ele é limitado e impreciso.

Segundo a neurociência, as limitações do alarme do sistema 1 são de três espécies ${ }^{93}$ : (i) ele responde mais a ofensas causadas como meio do que como efeito colateral (ou seja, ofensas dolosas, intencionalmente causadas); (ii) responde mais a ofensas causadas ativamente do que passivamente; (iii) responde mais a ofensas causadas diretamente pela força física, do que indiretamen$t e^{94}$. Ou seja, o alarme é sensível a atos de violência básica, prototipada, como estapear, bater, esmagar, empurrar.

Nesse momento, já é possível entender por que o sistema modular de alarme é míope. Não seria melhor que ele enxergasse todas as cadeias causais? Não, porque, caso isso ocorresse, o sistema simplesmente travaria. $\mathrm{Na}$ vida real, em vez das duas cadeias causais aqui estudadas de forma simplificada, existem múltiplas. Nosso cérebro não possui, ao que sabemos, capacidade cognitiva para rastrear e reagir rapidamente a tantas

89 GREENE, Joshua D. Moral Tribes: Emotion, Reason and the Gap Between Us and Them. New York: Penguin Books, 2013, p 126.

90 Essa integração, com a emoção como componente da razão, é o que diferencia a Teoria de Greene (GREENE, Joshua D. Moral Tribes: Emotion, Reason and the Gap Between Us and Them. New York: Penguin Books, 2013, p. 230) e de Mikhail (MIKHAIL, John. Elements of Moral Cognition: Rawl's Linguistic Analogy and the Cognitive Science of Moral and Legal Judgment. Cambridge, UK: Cambridge University, 2011. [Kindle]. location 1.355).

91 KAHNEMAN, Daniel. Thinking: fast and slow. New York: Farrar, Straus and Giroux, 2011. [Kindle]. location 2.080.

92 KAHNEMAN, Daniel. Thinking: fast and slow. New York: Farrar, Straus and Giroux, 2011. [Kindle]. location 323.

93 GREENE, Joshua D. Moral Tribes: Emotion, Reason and the Gap Between Us and Them. New York: Penguin Books, 2013. p. 247.

94 GREENE, Joshua D. Moral Tribes: Emotion, Reason and the Gap Between Us and Them. New York: Penguin Books, 2013. p. 246. Isso significa, também, que ele responde mais ativamente a possibilidades lesivas causadas por ações do que por omissões. Pior, essa descoberta aponta que nossos alarmes funcionam muito mal quando as lesões são causadas indiretamente. Por exemplo, é certamente instintivamente mais desconfortável disparar uma arma de fogo no rosto de alguém do que apertar um botão que pode disparar um míssil à distância, matando milhares de pessoas. Nossa intuição, para falar de um problema brasileiro, é no sentido de que os crimes de colarinho branco e de corrupção não geram a mesma revolta (nem as mesmas penas) dos crimes clássicos contra a vida - como o homicídio — por razões semelhantes. O tema é tratado no interessantíssimo trabalho de PAHAIA, Neeru; Karim S.; GREENE, Joshua D; BAZERMAN, Max H. Dirty Work, Clean Hands: The Moral Psychology of Indirect Agency. Organizational Behavior and Human Decision Processes. Disponível em: <https://dash.harvard.edu/handle/1/4264764>. Acesso em: 16 fev. 2018. 
cadeias assim. Como um computador sobrecarregado, ele travaria, o que acabaria por comprometer nossa sobrevivência em situações de risco ${ }^{95}$.

Um outro aspecto que escapa do sistema 1 são os benefícios eventualmente causados pela violência. Em uma versão do footbridge case, os participantes defrontam-se com a possibilidade de empurrar o funcionário da ponte e salvar milhares de pessoas (imagine-se que o bonde desgovernado baterá em um paiol de pólvora, próximo a uma represa, causando uma explosão e rompendo a barragem) ${ }^{96}$. Nesse caso, o percentual de aprovação foi a $70 \%$. Conquanto bem mais alto que os $31 \%$ originais, ele, anda, é inferior à aprovação moral do switch case $(87 \%)^{97}$.

Como pode o movimento de uma manivela que mata uma pessoa para salvar cinco vidas valer mais do que um empurrão que mata a mesma quantidade para salvar milhões? Claramente, nesse caso, o alarme do sistema 1 foi ativado por conta do empurrão, mas foi só parcialmente compensado pelo clamor dos números altos. A magnitude dos números certamente afetou o julgamento ${ }^{98}$, mas de forma totalmente desproporcional ao número de vidas em risco, tudo por conta do alarme do sistema 1. Sabemos o quanto isso soa desconfortável, mas a verdade é que os benefícios da violência no caso do paiol de pólvora não foram corretamente valorados pelas pessoas.

Um paralelo interessante entre neurociência e direito diz respeito à interpretação do art. 139, IV, do CPC/2015, especificamente no que concerne à execução/cumprimento de sentença de obrigação de pagar quantia certa. Existe grande resistência da doutrina de direito processual quando se trata de permitir a aplicação de meios executivos atípicos logo após o inadimplemento do devedor (após o prazo do art. 523 do CPC/2015). As resistências aumentam ainda mais quando se discutem quais seriam esses meios coercitivos/ indutivos corretos, com ponderações claramente pendentes às garantias processuais do devedor.

Como veremos, e provaremos, a utilização de meios executivos rigorosos pode produzir alto nível de cooperação no processo, elevando sobremaneira o nível de bem-estar social. Esse efeito, todavia, é sistêmico, sendo difícil visualizá-lo de imediato.

Por outro lado, esses atos estão realmente embutidos de certa violência voltada para uma pessoa determinada (o devedor). Quando surgem os debates, a evidente violência individualizada, contraposta ao benefício sistêmico e difuso, implica um debate no qual dificilmente a frieza da estatística superará as cores fortes da violência individualizada (normalmente traduzidas em expressões como processo justo ou devido processo legal).

Por exemplo, o alarme acionado pela concretude $e^{99}$ do drama de um devedor que tem sua $\mathrm{CNH}$ ou o seu passaporte retido (sistema 1), possivelmente superará, no debate, os benefícios sistêmicos quase invisíveis que podem ser gerados quando se estabelece uma jurisprudência rigorosa para o cumprimento de decisões judiciais (credible threat) ${ }^{100}$.

Sistema 1 e sistema 2 desenvolveram-se e funcionam juntos. A quase totalidade da história natural do homo

95 GREENE, Joshua D. Moral Tribes: Emotion, Reason and the Gap Between Us and Them. New York: Penguin Books, 2013. p. 238-239. A metáfora do computador é nossa.

96 PAXTON, Joseph M.; UNGAR, Leo; GREENE, Joshua D. Reflection and Reasoning in Moral Judgment. Cognitive Science, v. 36, n. 1, p. 163-177, jan./ fev. 2012. O exemplo foi um pouco modificado por nós.

97 GREENE, Joshua D. Moral Tribes: Emotion, Reason and the Gap Between Us and Them. New York: Penguin Books, 2013. p. 248.

98 PAXTON, Joseph M.; UNGAR, Leo; GREENE, Joshua D. Reflection and Reasoning in Moral Judgment. Cognitive Science, v. 36, n. 1, p. 163-177, jan./ fev. 2012. p. 252.

99 Para usar o termo de Pinker, já referido. Ocorre que, assim como números altíssimos de vidas a serem protegidas tiveram algum impacto na aprovação do footbridge case (quando ele está prestes a romper a barragem), também o cenário de tragédia da Justiça, e principalmente da execução no Brasil, começa a abrir espaço para uma postura mais pragmática da doutrina e da jurisprudência. 100 A ameaça crível (ou credible threat) é necessária para que as partes alterem suas estratégias em um determinado jogo, passando, muitas vezes, a adotar uma postura cooperativa. No caso específico do cumprimento de sentença que condena no pagamento de quantia certa, a ideia cooperativa por excelência é o cumprimento da sentença no prazo do art. 523 do CPC/2105. A ameaça real de um "mal maior", entra na conta de utilidade do devedor, que pondera de forma mais rigorosa as consequências do inadimplemento, ajustando seu comportamento. 
sapiens é selvagem e pode ser vista como uma luta pela sobrevivência cotidiana, com enfrentamento de perigos fisicamente próximos e prática de atos violentos cujas consequências não iam muito além dos limites físicos de quem os perpetrava ${ }^{101}$.

A partir do momento em que não somos mais selvagens e em que criamos sociedades desenvolvidas e globalizadas, nós aprimoramos nossas ferramentas e temos, cada vez mais, tecnologia para medir os custos e benefícios de nossas escolhas. Os atos potencialmente mais violentos (nocivos e perigosos) de hoje decorrem do aperto de um botão de disparo atômico ou do desvio silencioso ilícito de recursos públicos, e não de uma agressão a uma pessoa próxima ${ }^{102}$.

A busca adequada do bem comum, por sua vez, depende do desenho de políticas públicas pensadas ex ante para beneficiar o maior número de pessoas, sendo mesmo inevitável que, ex post, algumas delas sejam prejudicadas.

É na ponderação consciente entre custos e benefícios, jamais perdendo de vista os vieses e heurísticas causados pelo dual process mode, que o Estado pode maximizar seu papel de gerador de bem-estar social.

É exatamente na seara da confecção de políticas públicas, iluminada pela descoberta dessa forma dual de pensar e de como realizamos nossos juízos morais, que surge a atualização da filosofia utilitarista, chamada por alguns de pragmatismo profundo ${ }^{103}$.

\section{Pragmatismo profundo e políticas públicas: Como debater QUestões difíceis, PASSÍVEIS DE REGULAÇÃO PELO DIREITO}

Como procuramos demonstrar, a neurociência da moralidade alerta que, conquanto importantíssimas, as intuições do sistema 1 não devem ser elevadas à condição de princípios categóricos, inviabilizando a ponderação entre custos e benefícios de atos a priori violentos ${ }^{104}$.

101 O gráfico abaixo mostra que o desenvolvimento das potencialidades do homo sapiens foi estável por milhares de anos, sofrendo uma guinada apenas recentemente, mais especificamente após a revolução industrial. (MORRIS, Ian. Why the West Rules: For Now: The Patterns of History and What They Reveal About the Future. New York: Farrar, Straus and Giroux, 2010. [Kindle]. location 2.638).

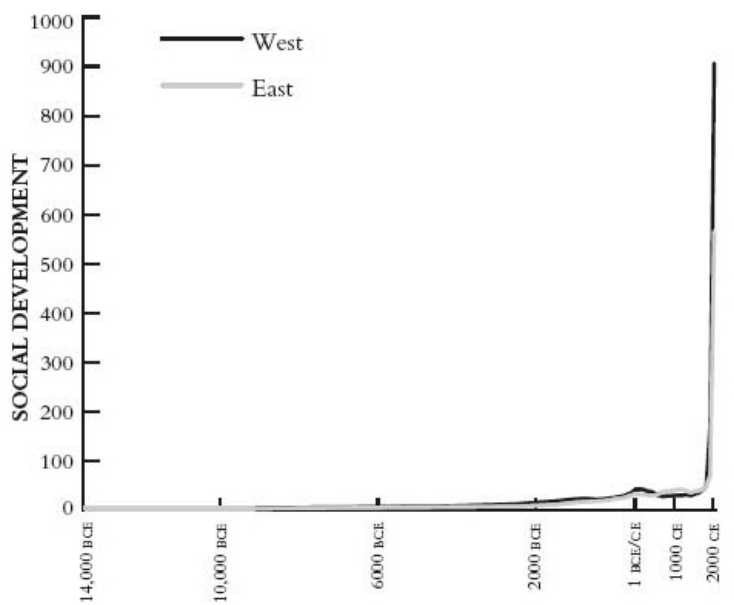

102 Obviamente, não estamos defendendo as agressões pessoais, que continuam sendo abomináveis. O que pretendemos é apontar para a insuficiência do alarme mental automático quando se trata de lidar com atos nocivos impessoais, cada vez mais comuns na era da tecnologia avançada.

103 GREENE, Joshua D. Moral Tribes: Emotion, Reason and the Gap Between Us and Them. New York: Penguin Books, 2013, p. 289.

104 GREENE, Joshua D. The Rat-a-gorical Imperative: Moral Intuition and the Limits of Affective Learning. Cognition. no prelo [aceito 6 mar. 2017]. Disponível em: <https://static1.squarespace.com/static/54763f79e4b0c4e55ffb000c/t/594d6a53a5790aaf12 
Nossa indisposição ao uso de força pessoal, à colocação do ser humano como meio causal primário ou às condutas ativas violentas não implica que esses atos sejam intrinsecamente ruins, independentemente de suas consequências, mas sim que nosso sistema 1, dentro de suas limitações cognitivas, elegeu as formas mais básicas, perceptíveis e evidentes de violência para emitir um alerta, auxiliando na tomada de decisões rápidas. Trata-se um importante diferencial evolutivo.

Esse desvendamento da forma de funcionamento do cérebro (dualprocess model) tem impactos diretos em questões absolutamente sensíveis, como tortura, pena de morte, prisão perpétua, guerras, aborto e outras. Isso não significa, todavia, que sejamos favoráveis a todas elas. Existem boas razões utilitaristas para oposição ou defesa de algumas delas e a resposta, ao final do dia, depende, sempre, de uma ponderação entre custos e benefícios.

O problema é que a mesma cegueira que não permite enxergar determinados benefícios derivados de atos aparentemente violentos também esconde os malefícios de posturas e políticas aparentemente inofensivas, como aquelas que atacam o meio ambiente, por exemplo, ou que tratam as pessoas de forma desigual sem qualquer motivo, como os casos de corrupção e favorecimento pessoal, claramente subvalorizados pelo sistema penal quando comparados com crimes violentos clássicos, como o homicídio ou o latrocínio.

O mesmo ocorre no sistema processual. Quase todas as abordagens do Princípio do Devido Processo Legal (ao menos em países de civil law) partem de princípios absolutos de justiça, atrelados a garantias fundamentais a serem preservadas a qualquer custo, ainda que esse custo seja uma ineficiência sistêmica e uma tragédia não cooperativa que prejudique toda a sociedade. Em nosso sentir, contraditório, ampla defesa e outras derivações do devido processo legal são importantes não porque têm valor absoluto, mas sim pela sua contribuição para que o sistema de justiça funcione de modo mais efetivo, trazendo o maior conforto e bem-estar possível para o maior número de pessoas.

A neurociênica da moralidade vai longe, discutindo, de forma pragmática, diversos temas difíceis, muitas vezes sem conclusão definitiva. A ponderação entre custos e benefícios, de forma sistêmica, como exige-se no esboço de políticas públicas, é certamente uma tarefa árdua. Há, dentro dessa filosofia, discussões interessantíssimas sobre o que é bom, o que é felicidade, como ela pode ser medida, qual o valor da liberdade e da democracia, além de muitas outras questões.

Para os limites deste artigo, todavia, basta lembrarmos de como funciona nosso cérebro e de onde vêm nossas intuições morais. Posto isso, é necessário que não se lhes dê, a priori, valor absoluto, buscando-se sempre uma ponderação possível entre custos e benefícios, principalmente quando se trata de buscar os melhores desenhos para políticas públicas, de lege ferenda ou de lege lata.

Para problemas difíceis, não há solução mágica. Uma abordagem pragmática, todavia, jamais rejeitará qualquer hipótese por princípio. Dentro da premissa do Estado Democrático de Direito, a jurisprudência e a administração pública somente podem atuar nos limites da lei, mas a hermenêutica deve ser, dentro do possível, preservada de nossos impulsos ideológicos dissociados da efetiva busca do bem-estar social.

Uma das premissas do pragmatismo profundo é a de que a dificuldade de resolver questões difíceis decorre do fato de que cada tribo (aqui incluídos grupos sociais, países, etnias e culturas) possui seus próprios instintos de certo e errado, ou seja, suas configuraçôes específicas do sistema 1, forjadas por cultura, meio ambiente, religião e experiências de vida ${ }^{105}$. Discussões sobre o valor intrínseco dessas questões, portanto, tendem, apenas,

07eb76/1498245716080/greene-rat-a-gorical-cogn-17.pdf>. Acesso em: 16 fev. 2018.

105 GREENE, Joshua D. Moral Tribes: Emotion, Reason and the Gap Between Us and Them. New York: Penguin Books, 2013, p. 291. Experimento recente demonstrou divergências na moralidade ao longo de culturas bastante diferentes, que conferem graus diferentes à importância da intenção por detrás das ações (moral intent hypotesis). Em sociedade menores, os padrões são bem mais variáveis do que em sociedades industrializadas. (BARRETT, H. Clark; BOLYANATZ, Alexander; CRITTENDEN, Alyssa N.; FESSLER, Daniel M. T.; FITZPATRICK, Simon; GURYEN, Michael; HENRICH, Joseph; KANOVSKY, Martin; KUSHNICK, Geoff; PISOR, Anne, SCLEZA, Brooke A.; STICH, Stephen; VON RUEDEN, Chris; ZHAO, Wanying; LAURENCE, Stephen. Small-scale societies exhibit fundamental variation in the role of intentions in moral judgment. PNAS, v. 113, n. 17, abr. 2016). 
a aprofundar as diferenças. ${ }^{106} \mathrm{~A}$ única solução, portanto, seria estabelecer uma moeda comum, uma espécie de medidor metamoral para buscar soluções de consenso. Para Greene, e para qualquer utilitarista, essa moeda é a felicidade, pelo simples fato de que, independentemente de nossas convicções morais, todos queremos ser felizes $^{107}$.

O que diferencia o pragmatismo do pragmatismo profundo é a intenção explícita de deixar de lado as diferenças intrínsecas de julgamento para questões difíceis e trabalhar a felicidade como bússola moral a guiar essas discussões ${ }^{108}$.

Segundo Greene, o segredo do pragmatismo é utilizar a forma correta de pensarpara o tipo correto de problema. Para problemas básicos do dia a dia, o sistema 1 funciona muito bem. Para problemas mais complexos, aí incluído o desenho de politicas públicas, é o sistema 2 que tem de ser preponderantemente utilizado ${ }^{109}$.

A ideia básica é: quando os interesses dos envolvidos conflitarem, utilizar o modo manual de pensar ${ }^{110}$. A dificuldade básica é: como alterar a forma de pensar do modo automático para o modo manual?

Segundo Botvinick e March ${ }^{111}$, o cérebro resolve esse problema utilizando um monitoramento de conflito, que funciona em uma estrutura chamada córtex cingulado anterior (anterior cingulate cortex - ACC). A estrutura é ativada, sempre, que respostas incompatíveis aparecem simultaneamente ${ }^{112}$ emitindo um sinal para o DLPFC (dorso lateral, sistema 2), que ativa o modo manual. Comprovadamente, dilemas morais difíceis, quando discutidos, ativam tanto o ACC quanto o DLPFC ${ }^{113}$.

Quando se debatem temas controvertidos, nosso primeiro impulso é argumentar a partir do que julgamos correto. O pragmatismo profundo propõe que se deixem de lado as preconcepções e que haja um engajamento colaborativo na busca da solução capaz de maximizar o bem-estar social. Note-se que o pragmatismo não ensina qual o exato caminho a ser percorrido, mas pressupõe que problemas difíceis são encaminhados a partir de argumentos concretos, dados e pesquisas ${ }^{114}$.

É preciso fugir daquilo que Rozemblid e Keil identificaram como the illusion of explanatory depth ${ }^{115}$. Por uma questão de conforto cognitivo ${ }^{116}$, as pessoas imaginam entender, profundamente, aquilo que elas sequer compreendem. Trata-se de uma derivação do viés de otimismo, que atinge, inclusive, especialistas na matéria da discussão provocadora da ilusão de entendimento ${ }^{117}$.

106 POSNER, Richard A. Law, Pragmatism and Democracy. Cambridge, MA; London: Harvard University, 2003. p. $143-154$.

107 GREENE, Joshua D. Moral Tribes: Emotion, Reason and the Gap Between Us and Them. New York: Penguin Books, 2013. p. 291; MILL, John Stuart. Utilitarianism and the 1896 Speech on Capital Punishment. 2. ed. Indianápolis: George Sher, 2001. [Kindle]. p. 6-26.

108 GREENE, Joshua D. Moral Tribes: Emotion, Reason and the Gap Between Us and Them. New York: Penguin Books, 2013. p. 292.

109 GREENE, Joshua D. Moral Tribes: Emotion, Reason and the Gap Between Us and Them. New York: Penguin Books, 2013. p. 292.

110 GREENE, Joshua D. Moral Tribes: Emotion, Reason and the Gap Between Us and Them. New York: Penguin Books, 2013. p. 293.

111 BOTVINICK, Matthew M.; BRAVER, Todd S.; BARCH, Deanna M.; CARTER, Cameron S.; COHEN, Jonathan D. Conflict Monitoring and Cognitive Control. Psychological Review, v. 108, n. 3, p. 624-652, 2001.

112 Por exemplo, quando a palavra "vermelho" aparece escrita em verde, como vimos no color-naming Stroop task.

113 GREENE, Joshua D. et al. The Neural Bases of Cognitive Conflict and Control in Moral Judgment. Neuron, v. 44, p. 389-400, 14 out. 2004; CUSHMAN, F. et al. Judgment Before Principle: Engagement of the Frontoparietal Control Network in Condemning Harms of Omission. Social Cognitive and Affective Neuroscience, v. 7, n. 8, p. 888-895, nov. 2012.

114 Nada muito diferente do que sempre alertava Barbosa Moreira, quando comentava da dificuldade de discutirem-se alterações processuais sem pesquisa empírica. (BARBOSA MOREIRA, José Carlos. As reformas do Código de Processo Civil: condições de uma avaliação objetiva. In: Temas de Direito Processual Civil. São Paulo: Saraiva, 1997, p. 81-94.).

115 Nas palavras dos autores: "People feel they understand complex phenomena with far greater precision, coherence, and depth than they really do; they are subject to an illusion — an illusion of explanatory depth. The illusion is far stronger for explanatory knowledge than many other kinds of knowledge, such as that for facts, procedures or narratives." (ROZENBLIT, Leonid; KEIL, Frank. The Misunderstood Limits of Folk Science: An Illusion of Explanatory Depth. Cognitive Science, v. 26, n. 5, p. 521-562, set. 2002).

116 KAHNEMAN, Daniel. Thinking: fast and slow. New York: Farrar, Straus and Giroux, 2011. [Kindle]. location 940.

117 KAHNEMAN, Daniel. Thinking: fast and slow. New York: Farrar, Straus and Giroux, 2011. [Kindle]. location 3.923. 
Por exemplo, quando se discutem os recortes dos princípios do devido processo legal, são comuns as referências à legitimação pela participação, à dignidade da pessoa humana e à busca da verdade no processo. Mas até que ponto cada uma das caraterísticas do devido processo legal realmente colabora no alcance desses objetivos? Quais são as consequências positivas e negativas de um determinado modelo de processo? Como calcular os custos envolvidos e em que medida isso impacta no bem-estar social? Esses temas são pouco discutidos, não somente no Brasil, mas na maioria dos países de tradição europeia continental.

Greene sustenta que, nas discussões sobre temas difíceis, há uma confusão entre razão e racionalização ${ }^{118}$. Razão seria algo que se busca com pesquisas e argumentos concretos. Já a racionalização estaria mais para um adorno teórico que moldura nossos instintos. Algo muito próximo do que os neurocientistas chamam de confabulação (confabulation) ${ }^{119}$.

O ponto do pragmatismo profundo permanece: se os desacordos sobre questões difíceis decorrem de diferenças no sistema 1 herdadas de experiências nossas ou de nossos antepassados, qualquer discussão ancorada nessas intuições tende ao fracasso ${ }^{120}$. O sistema 1 é, nesse sentido, cognitivamente impenetrável ${ }^{121}$. Qualquer avanço interlocutório tem de ser guiado por reflexões típicas do sistema 2, ou seja, aquelas capazes de promover o maior bem-estar possível entre os envolvidos ${ }^{122}$.

No trato específico do direito, suspeitamos que posições peremptórias sobre temas difíceis, fundadas em dogmas impenetráveis que não encontram um amparo explícito na Constituição Federal, trajam as vestes do sistema $1^{123}$.

Veja-se, por exemplo, o tema da vinculação das cortes inferiores aos precedentes estabelecidos pelas Cortes Superiores, na forma do art. 926 do CPC/2015. Afora nuances, não há norma explícita na Constituição Federal que torne inconstitucionais os precedentes apontados pelo CPC/2015 como obrigatórios. Não estamos afirmando que não seja possível tecer argumentos pela inconstitucionalidade da obrigatoriedade do respeito aos precedentes, ou mesmo discutir qual é o grupo de precedentes obrigatórios e ou vinculantes. Essa é, no fim do dia, uma questão de interpretação da norma constitucional. E o diabo reside exatamente nesse ponto.

Nesse tipo de discussão, o sistema 2 ancora sua racionalização em determinados valores fornecidos pelo sistema 1, criando-se um debate que deixa de lado o que verdadeiramente importa: o bom funcionamento do sistema judicial, de acordo com as circunstâncias brasileiras. Quais os problemas e virtudes do sistema

118 GREENE, Joshua D. Moral Tribes: Emotion, Reason and the Gap Between Us and Them. New York: Penguin Books, 2013. p. 302-309.

119 Pacientes com danos cerebrais como amnésia ou desconexão dos hemisférios (split-brain) tendem a criar enredos fidedignos para preencher os evidentes brancos mentais. Note-se que o dano mental não cria a capacidade de confabulação. Todos nós somos confabuladores (GREENE, Joshua D. Moral Tribes: Emotion, Reason and the Gap Between Us and Them. New York: Penguin Books, 2013. p. 299) e em uma discussão de política pública isso deve ser levado bastante sério. O equivalente moral da confabulação é a racionalização (GREENE, Joshua D. Moral Tribes: Emotion, Reason and the Gap Between Us and Them. New York: Penguin Books, 2013. p. 300), uma roupagem teórica para os nossos instintos. (STUSS, D. T. et al. An Extraordinary Form of Confabulation. Neurology, v. 28, n. 11, p. 1.166-1.172, nov. 1978). Sobre pacientes com split-brain: GAZZANIGA, Michael. One Brain or Two? The Split Brain in Man. Scientific American, v. 217, n. 2, p. 24-29, 1967.

120 Esse é um forte argumento para a visão pragmática schumpeteriana, defendida por Posner (POSNER, Richard A. Law, Pragmatism and Democracy. Cambridge, MA; London: Harvard University, 2003).

121 GREENE, Joshua D. Moral Tribes: Emotion, Reason and the Gap Between Us and Them. New York: Penguin Books, 2013. p. 303.

122 Para um exemplo sobre as dificuldades desse caminho, e sobre como ele pode ser percorrido, ver discussão a respeito da possibilidade de aborto em GREENE, Joshua D. Moral Tribes: Emotion, Reason and the Gap Between Us and Them. New York: Penguin Books, 2013. p. 309.

123 Não obstante, é crescente o número de artigos brasileiros que partem de uma premissa utilitarista, essencialmente preocupada com o aumento do bem estar-social quando da interpretação da norma jurídica. Nesse sentido: SILVA, Juvêncio Borges; JUCATELLI, João Paulo. Judicialização da saúde, ativismo judicial e o consequente desequilíbrio do orçamento público. Revista Brasileira de Políticas Públicas, v.7, n. 1, p. 99-116, 2017. SANTANA, Héctor Valverde. Análise econômica do direito: a eficiência da norma jurídica na prevenção e reparação de danos sofridos pelo consumidor. Revista Brasileira de Políticas Públicas, v.4, n. 1, p. 224-337, 2014. , Matthew M.; BRAVER, Todd premissa pragmatista por nlitarista, essencialmente preocupada com o aumento do bem estar-socail 
de justiça brasileiro? Quais os benefícios concretos da adoção de um sistema de precedentes vinculantes? Quais os possíveis malefícios? Entre prós e contras, no geral, a adoção implicaria um sistema mais eficiente para a sociedade como um todo? ${ }^{124}$

Essas perguntas, para serem respondidas, precisam, necessariamente, do aporte de outras ciências, como a economia, a psicologia e a sociologia, além de pesquisas empíricas. Mais do que isso, essa resposta pode mudar ao longo do tempo, de acordo com as circunstâncias. Não há uma resposta de fé para esse tipo de questão. Qualquer princípio absoluto de direito processual do qual não se arrede pé parece mais um escudo para as racionalizações dos instintos do sistema 1 do que um argumento consistente ${ }^{125}$.

\section{Considerações finais}

De forma geral, identificamos que, nas discussões difíceis que normalmente antecedem a tomada de decisões jurídicas complexas e o desenho de políticas públicas, argumentos exclusivamente valorativos ou principiológicos são um passe livre intelectual, um atalho preguiçoso, instintivo, às vezes, autoritário, e, simplesmente, deixa de lado o que realmente importa: a realidade. Pessoas não vivem argumentos. Vivem a vida. O que define a correção de um posicionamento sobre um tema difícil é, em última instância, uma questão empírica.

O pragmatismo profundo reserva aos direitos um papel fundamental na sociedade: conferir segurança para temas que estejam mais ou menos assentados, não porque sejam verdades universais, mas porque, por razões práticas, os membros daquela determinada sociedade concordam com a solução e não estão dispostos a discuti-la a todo instante ${ }^{126}$. Nesses casos, o risco de a escolha protegida com um direito ser incorreta é menor do que o risco de não haver uma firme resolução a respeito.

Todavia, nos temas difíceis, para os quais não haja norma escrita ou jurisprudencial clara, a revisão de literatura demonstrou a existência de um corpo consistente de experimentos que demonstram que o debate deve centrar-se na pesquisa dos benefícios e dos malefícios daquele posicionamento para a coletividade, apesar de a nossa intuição forçar-nos a decidir com base em convicções principiológicas, muitas vezes dissociadas da realidade. Ficou claro que o entendimento de como o cérebro funciona é fundamental para superar esse problema e mudar as premissas utilizadas nas escolhas públicas.

Quando se trata da busca do que é melhor para a sociedade, ao menos no que se refere ao desenho de políticas públicas, não há fórmulas mágicas. O aumento do bem-estar social e a utilização de métodos científicos teóricos e empíricos, todavia, são premissas inafastáveis.

\section{REFERÊNCIAS}

BARON, J.; GREENE, J. D. Determinants of Insensitivity to Quantity in Valuation of Public Goods: Contribution, Warm Glow, Budget Constraints, Availability, and Prominence. Journal of Experimental Psychology, v. 2, n. 2, p. 107-125, 1996.

BARRETT, H. Clark et al. Small-scale societies exhibit fundamental variation in the role of intentions in moral judgment. PNAS, v. 113, n. 17, abr. 2016.

124 Todavia, abordando o tema com a premissa pragmatista por nós proposta, GICO Jr., Ivo. Anarquismo Judicial e Segurança Jurídica. Revista Brasileira de Políticas Públicas, v. 5, n. especial, p. 480-500, 2015.

125 Sobre direitos como escudos e armas, para o bem e para o mal: GREENE, Joshua D. Moral Tribes: Emotion, Reason and the Gap Between Us and Them. New York: Penguin Books, 2013, p. 306-309.

126 GREENE, Joshua D. Moral Tribes: Emotion, Reason and the Gap Between Us and Them. New York: Penguin Books, 2013, p. 306. 
BECHARA, Antonie et al. Insensitivity to Future Consequences Following Damage to Human Prefrontal Cortex. Cognition, v. 50, p. 7-15, 1994.

BLAIR, R. J. R. A Cognitive Developmental Approach to Morality: Investigating the Psychopath. Cognition, v. 57, p. $1-29,1995$.

BOTVINICK, Matthew M. et al. Conflict Monitoring and Cognitive Control. Psychological Review, v. 108, n. 3, p. 624-652, 2001.

CALABRESI, Guido. The Future of Law and Economics. New Haven, CT: Yale University, 2016.

COHEN, Jonathan D.; MILLER, Earl K. An Integrative Theory of Prefrontal Cortex Function. Annual Review of Neuroscience, v. 24, p. 167-202, 2001.

CUSHMAN, F.; GAFFEY, A.; GRAY, K.; MENDES, W. B. Simulating Murder: The Aversion to Harmful Action. Emotion, v. 12, n 1, p. 2-7, 2012. Disponível em: <https://cushmanlab.fas.harvard.edu/docs/ cushman_gray_gaffey\&mendes_2012.pdf>. Acesso em: 30 jul. 2017.

CUSHMAN, F.; GREENE, J. D. The Philosopher in the Theater. In: MIKULINCER, M.; SHAVER, P. R. (Eds.). Social Psychology of Morality: The Origins of Good and Evil. APA, 2011. Disponível em: < http:// cushmanlab.fas.harvard.edu/docs/cushman\&greene_2011b.pdf>. Acesso em: 16 fev. 2018.

CUSHMAN, F. et al. Judgment Before Principle: Engagement of the Frontoparietal Control Network in Condemning Harms of Omission. Social Cognitive and Affective Neuroscience, v. 7, n. 8, p. 888-895, nov. 2012.

CUSHMAN, F.; YOUNG, L.; HAUSER, M. The Role of Conscious Reasoning and Intuition in Moral Judgment: Testing Three Principles of Harm. Psychology Science, v. 17, n. 12, p. 1.082-1.089, 2006.

DAMASIO, Antônio. Descartes' Error: Emotion, Rationality and the Human Brain. New York: Penguim; Grosset, 1994. [Kindle].

DESVOUSGES, William H. et al. Measuring Nonuse Damages Using Contingent Valuation: An Experimental Evaluation of Accuracy. 2. ed. Research Triangle Park, NC: RTI, 2010. Disponível em: < https://www.rti. org/sites/default/files/resources/bk-0001-1009_web.pdf>. Acesso em: 16 fev. 2018.

FOOT, Philippa. The Problem of Abortion and the Doctrine of the Double Effect. Oxford Review, n. 5, p. 5-15, 1967.

FRANKISH, Keith. Dual-Process and Dual-System Theories of Reasoning. Philosophy Compass, v. 5, n. 10, p. 914-926, 2010.

GAZZANIGA, Michael. One Brain or Two? The Split Brain in Man. Scientific American, v. 217, n. 2, p. 2429, 1967.

GICO Jr., Ivo. Anarquismo Judicial e Segurança Jurídica. Revista Brasileira de Políticas Públicas, v.5, número especial, p. 480-500, 2015.

GREENE, Joshua D. Moral Tribes: Emotion, Reason and the Gap Between Us and Them. New York: Penguin Books, 2013.

GREENE, Joshua D. The Rat-a-gorical Imperative: Moral Intuition and the Limits of Affective Learning. Cognition, no prelo [aceito 6 mar. 2017]. Disponível em: <https://static1.squarespace.com/ static/54763f79e4b0c4e55ffb000c/t/594d6a53a5790aaf1207eb76/1498245716080/greene-rat-a-goricalcogn-17.pdf>. Acesso em: 16 fev. 2018.

GREENE, Joshua D. et al. Cognitive Load Selectively Interferes with Utilitarian Moral Judgment. Journal of Cognitive Neuroscience, v. 22, n. 8, p. 1.888-1.899, jun. 2008.

GREENE, Joshua D. et al. The Neural Bases of Cognitive Conflict and Control in Moral Judgment. Neuron, 
v. 44, p. 389-400, 14 out. 2004.

GREENE, Joshua D. et al. An fMRI Investigation of Emotional Engagement in Moral Judgment. Science, v. 293 , n. 5.537, p. 2.105-2.108, set. 2001.

HAUSER, Marc et al. A Dissociation Between Moral Judgments and Justifications. Mind \& Language, v. 22, n. 1, p. 1-21, fev. 2007.

HUANG, Bert I. Book Review: Law and Moral Dilemmas. Harvard Law Review, v. 130, p. 659-699, dez. 2016.

KAHNEMAN, Daniel. Thinking: fast and slow. New York: Farrar, Straus and Giroux, 2011. [Kindle].

KAHNEMAN, Daniel; SHANE Frederick. Representativeness Revisited: Attribute Substitution in Intuitive Judgment. In: GILOVICH, Thomas; GRIFFIN, Dale; KAHNEMAN, Daniel (Eds.). Heuristics and Biases: The Psychology of Intuitive Judgment. Cambridge: Cambridge University, 2002. p. 49-81.

KANT, Immanuel. Fundamental Principles of the Metaphysics of Morals. Tradução: Thomas Kingsmill Abbott. [Kindle: The ultimate collected works of 14 books].

KAPLOW, Louis; SHAVELL, Steven. Fairness Versus Welfare. Harvard Law Review, v. 114, n. 4, p. 961-1.390, fev. 2001

LENZ, Gabriel S.; LAWSON, Chappell. Looking the Part: Television Leads Less Informed Citizens to Vote Based on Candidates' Appearance. American Journal of Political Science, v. 55, n. 3, p. 574-589, jul. 2011.

MCINTYRE, Alison. Doctrine of Double Effect. In: ZALTA, Edward N. (Ed.). The Stanford Encyclopedia of Philosophy, inverno 2014. Disponível em: < https://plato.stanford.edu/archives/win2014/entries/doubleeffect>. Acesso em: 16 fev. 2018.

MENDEZ, Mário F.; ANDERSON, E.; SHAPIRA, J. S. An Investigation of Moral Judgement in Frontotemporal Dementia. Cognitive Behavioral Neurology, v. 18, n. 4, p. 193-197, dez. 2005.

MIKHAIL, John. Elements of Moral Cognition: Rawl's Linguistic Analogy and the Cognitive Science of Moral and Legal Judgment. Cambridge, UK: Cambridge University, 2011. [Kindle].

MILL, John Stuart. Utilitarianism and the 1896 Speech on Capital Punishment. 2. ed., Indianápolis: George Sher, 2001. [Kindle].

MOREIRA, José Carlos Barbosa. As reformas do Código de Processo Civil: condições de uma avaliação objetiva. In: Temas de Direito Processual Civil. São Paulo: Saraiva, 1997, p. 81-94. [6. série].

MORETTO, Giovanna et al. A psychophysiological investigation of moral judgment after ventromedial prefrontal damage. Journal of Cognitive Neuroscience, v. 22, n. 8, p. 1.888-1.899, 2009.

MORRIS, Ian. Why the West Rules: For Now: The Patterns of History and What They Reveal About the Future. New York: Farrar, Straus and Giroux, 2010. [Kindle].

NEARY, Walter. Personal Decisions Exercise the Emotional Part of the Brain, 2001. Disponível em: <http://www. washington.edu/news/2001/11/26/personal-decisions-exercise-the-emotional-part-of-the-brain > . Acesso em: 16 fev. 2018

NEERGAARD, L. Brain Scan Shows Emotion in Decisions. Washington Post, set. 2001.

NOWAK, Martin A. Five Rules for the Evolution of Cooperation. Science, v. 314, n. 5.805, p. 1.560-1.563, 8 dez. 2006. Disponível em: <https://www.ncbi.nlm.nih.gov/pmc/articles/PMC3279745>. Acesso em: 16 fev. 2018.

PAHAIA, Neeru et al. Dirty Work, Clean Hands: The Moral Psychology of Indirect Agency. Organizational Behavior and Human Decision Processes. Disponível em: <https://dash.harvard.edu/handle/1/4264764 >. Acesso em: 16 fev. 2018. 
PAXTON, Joseph M.; UNGAR, Leo; GREENE, Joshua D. Reflection and Reasoning in Moral Judgment. Cognitive Science, v. 36, n. 1, p. 163-177, jan./ fev. 2012.

PINKER, Steven. The Stuff of Thought: Language as a Window Into Human Nature. New York: Penguin, 2007. [Kindle].

POSNER, Richard A. Law, Pragmatism and Democracy. Cambridge, MA; London: Harvard University, 2003.

ROZENBLIT, Leonid; KEIL, Frank. The Misunderstood Limits of Folk Science: An Illusion of Explanatory Depth. Cognitive Science, v. 26, n. 5, p. 521-562, set. 2002.

SANDEL, Michael. Justice: What's the Right Thing to Do? New York: Farrar, Straus and Giroux, 2008.

SANTANA, Héctor Valverde. Análise econômica do direito: a eficiência da norma jurídica na prevenção e reparação de danos sofridos pelo consumidor. Revista Brasileira de Políticas Públicas, v.4, n. 1, p. 224-337, 2014.

SCHWITZGEBEL, Eric; CUSHMAN, Fiery. Expertise in Moral Reasoning? Order Effects on Moral Judgment in Professional Philosophers and Non-Philosophers. Mind \& Language, v. 27, p. 135-153, 2012

SILVA, Juvêncio Borges; JUCATELLI, João Paulo. Judicialização da saúde, ativismo judicial e o consequente desequilíbrio do orçamento público. Revista Brasileira de Políticas Públicas, v.7, n. 1, p. 99-116, 2017.

STANOVICH, Keith E.; WEST, Richard F. Individual Differences in Reasoning: Implications for the Rationality Debate? Behavioral and Brain Sciences, v. 23, n. 5, p. 645-726, out. 2000.

STUSS, D. T.; ALEXANDER, M. P.; LIEBERMAN, A.; LEVINE, H. An Extraordinary Form of Confabulation. Neurology, v. 28, n. 11, p. 1.166-1.172, nov. 1978.

SUTER, Renata S.; HERTWIG, Ralph. Time and Moral Judgment. Cognition, v. 119, n. 3, p. 454-458, jun. 2011.

THOMAS, Bradley C. et al. Arrested Development: Early Prefrontal Lesions Impair the Maturation of Moral Judgement. Brain: A Journal of Neurology, v. 137, n. 4, p. 1.254-1.261, abr. 2014.

THOMAS, Bradley C.; CROFT, Katie E.; TRANEL, Daniel. Harming Kin to Save Strangers: Further Evidence for Abnormally Utilitarian Moral Judgments after Ventromedial Prefrontal Damage. Journal of Cognitive Neuroscience, v. 23, n. 9, p. 2.186-2.196, set. 2011.

THOMSON, Judith. Kamm on the Trolley Problems. In: KAMM, F. M. The Trolley Problem Mysteries. Oxford: Oxford University, 2016, p. 113-133. [Kindle].

THOMSON, Judith. Killing, Letting Die, and the Trolley Problem. Monist: Journal of General Philosophical Inquiry, v. 59, n. 2, p. 204-217, 1976.

THOMSON, Judith. The Trolley Problem. The Yale Law Journal, v. 94, n. 6, p. 1.395-1.415, maio 1985.

TODOROV, Alexander; BARON, Sean G.; OOSTERHOF Nikolaas N. Evaluating Face Trustworthiness: a Model Based Approach. Social Cognitive and Affective Neuroscience, v. 3, n. 2, p. 119-127, jun. 2008.

TODOROV, Alexander et al. Inferences of Competence from Faces Predict Election Outcomes. Science, v. 308, n. 5.728, p. 1.623-1.626, 10 jun. 2005.

TODOROV, Alexander; PAKRASHI, Manish; OOSTERHOF Nikolaas N. Evaluating Faces on Trustworthiness after Minimal Time Exposure. Social Cognition, v. 27, n. 6, p. 813-833, 2009.

XIANG, Xin. Would the Buddha Push the Man Off the Footbridge?: Systematic Variations in the Moral Judgment and Punishment Tendencies of Han Chinese, Tibetans and Americans. 2014. Monografia--(Trabalho de Conclusão de Curso). Harvard University, Cambridge, MA, 2014. 
Para publicar na revista Brasileira de Políticas Públicas, acesse o endereço eletrônico www.rbpp.uniceub.br

Observe as normas de publicação, para facilitar e agilizar o trabalho de edição. 